\title{
Vertical Integration, Competition, and Financial Exchanges: Is there Grain in the Silo?
}

\author{
Steffen Juranek ${ }^{\mathrm{a}, \mathrm{c}}$ \& Uwe Walz ${ }^{\mathrm{b}, \mathrm{c}}$
}

This version: December 2010

\begin{abstract}
We investigate the incentives for vertical or horizontal integration in the financialsecurity service industry, consisting of trading, clearing and settlement. We thereby focus on firms' decisions but also look on the implications of these decisions on competition and welfare. Our analysis shows that the incentives for vertical integration crucially depend on industry as well as market characteristics. A more pronounced demand for liquidity clearly favors vertical integration whereas deeper financial integration increases the incentives to undertake vertical integration only if the efficiency gains associated with vertical integration are sufficiently large. Furthermore, we show that market forces can suffer from a coordination problem that end in vertically integrated structures that are not in the best interest of the firms. We believe this problem can be addressed by policy measures such as the TARGET2-Securities program. Furthermore, we use our framework to discuss major industry trends and policy initiatives.
\end{abstract}

Keywords: vertical integration, horizontal integration, competition, trading, settlement

JEL classification: G15, L13, L22

${ }^{a}$ Goethe University Frankfurt Address: Goethe University Frankfurt, Grüneburgplatz 1, 60323 Frankfurt am Main, Germany. Tel: +49 (0) 69 79834806. E-mail: juranek@wiwi.uni-frankfurt.de

${ }^{\mathrm{b}}$ Goethe University Frankfurt and Center for Financial Studies. Address: Goethe University Frankfurt, Grüneburgplatz 1, 60323 Frankfurt am Main, Germany. Tel: +49 (0) 69 79834821. E-mail: uwe.walz@wiwi.uni-frankfurt.de

${ }^{c}$ We are grateful to Kai-Oliver Maurer and Martin Reck (Deutsche Börse) as well as their teams for very helpful conversations on the structure of the industry. Furthermore, we would like to thank participants in the CFS round table on the economics of exchanges for comments on an earlier version of the paper. The paper benefitted significantly from comments and suggestion by seminar participants at the CFS conference on the Industrial Organization of Securities Markets, 2010, the EEA Meeting in Glasgow 2010, the Verein für Socialpolitik Annual Conference 2010 as well as the House of Finance Seminar Series, Frankfurt. 


\section{Introduction}

Security exchanges and central security depositories (CSDs) are at the center of modern capital markets around the world. However, across continents and markets, we observe very different industry structures. On the one hand, we find a much more fragmented structure in Europe with more than 40 exchanges and roughly 20 CSDs (cf. FESE (2008)) as compared to the U.S. market with only a dozen exchanges and only two CSDs. On the other hand, the degree of vertical integration differs significantly among European countries and markets with, for example, strong vertical integration in Germany and much less vertical integration in other markets such as the United Kingdom.

At the same time, industry observers as well as policy makers expect further consolidation and change in the financial-security service industry (consisting of security exchanges and CSDs) in the years to come (see Economist (2006)). While all observers agree that changes in industry are under way, it is much less clear which direction these changes will take and what is desirable from the point of view of industry participants and society as a whole.

Against this background our analysis aims to provide some insights into the dynamics of the industrial organizations of the financial-security service industry, most notably into the interrelation of organizational design and market structure. Thereby, our main research questions are: Under what circumstances are vertical or horizontal integration more attractive? What does this do to the industrial organization of the industry? Which organizational and industrial structures are preferable from a welfare point of view? We thereby concentrate on vertical integration, or to put it using the subtitle of our paper: what are the advantages (the grain) of vertical integration (the silo)? On the basis of our answers to these questions, we also address recent industry development and regulatory initiatives and ask how these developments and initiatives affect the industrial organization of the financial-security service industry.

We take up these general research questions and investigate the drivers behind vertical as opposed to horizontal integration in the financial-security service industry. Our analysis shows that the incentives for vertical integration depend on industry and market characteristics such as the degree of financial market integration as well as the role that the liquidity effect plays for traders. We show that the more pronounced traders' preferences for liquidity the more pronounced the incentive to vertically integrate. This is not only true absolutely (i.e., with respect to the decision to vertically integrate or to stay completely non-integrated) but also in comparison to the decision to integrate horizontally.

At the same time, our theoretical reasoning suggests that vertical integration harms competitors. We show that financial-security service providers might fall into a coordi- 
nation trap. If it is profitable for one exchange to integrate vertically, the incentives for further firms to vertically integrate increase. This trend can lead to a bad equilibrium in which firms are in sum worse off than compared to a situation in which the industry is completely non-integrated. This point becomes more important if one thinks about an industry that starts with a certain degree of vertical integration due to, e.g., historical circumstances. When comparing vertical and horizontal integration, we find that the market solution has a tendency for too much vertical integration if the liquidity effect is sufficiently low. We interpret measures such as TARGET2-Securities as policy instruments to provide politically enforced horizontal integration that can overcome this tendency.

We extend our model by considering listing decisions and OTC (Over-The-Counter) trading. We argue that vertical integration decreases the market coverage of listed securities for which firms have to be compensated by lower listing fees. Similarly, the larger the OTC market in respective asset classes the lower are the incentives for vertical integration. Furthermore, we use our framework to discuss major industry trends and policy initiatives. We argue that vertical integration is an instrument to protect an exchange's home market against new competitors, such as Multilateral Trading Facilities, but new pricing schemes such as Maker-Taker pricing and the emergence of Algo-Trading might reduce the incentives to integrate vertically.

To derive these results, we propose a stylized model that depicts the interrelation between the organizational design of financial-security service providers and the competition among them. The model incorporates economies of scope as well as network effects at the different levels of the value chain of the financial-security service industry. We delineate traders' preferences for securities listed and traded on different exchanges by employing the Salop-model. Traders as well as exchanges are exogenously located on this circle depicting the concept of a natural affinity of certain traders for certain exchanges (e.g., due to language barriers, home bias, etc). We allow for competition among three exchanges. The securities listed on a certain exchange are settled in the associated (potentially organization-wise) independent CSD. We neglect custodian banks and therefore provide a barebones picture of the industry and the competition therein. We view vertical integration as a measure to implement a highly specific relation between an exchange and the associated CSD that makes trades routed through this link less costly but impose additional costs to trades that are settled outside the associated CSD or traded on another exchange but settled in the associated CSD. In that sense our idea of vertical integration is close in spirit to Grossman and Hart (1986). It also resembles the idea of vertical integration in the financial-security service industry as a decision for a closed rather than an open standard that makes external linkages partially incompatible with internal processes. Horizontal integration on the level of CSDs, in turn, is modeled as 
uniform cost-reductions displaying the concept of economies of scale and scope at this layer.

Our paper is related to several strands of the literature on the financial-securities service industry. First, our paper touches on the topic of competition between trading platforms. This is analyzed in different manners by, e.g., Foucault and Parlour (2004), Di Noia (2002), and Shy and Tarkka (2001) where the latter also involve a vertical relation between the brokers and stock exchanges. But all these papers focus on the role of alliances between stock exchanges, i.e., cooperation on a horizontal level whereas we focus on vertical cooperation.

Second, our paper has analogies to the question of interlinking securities settlement systems as is analyzed by Kauko (2004) and Kauko (2007).

Third, our work is directly related to the literature on vertical integration in the financial-securities service industry. Köppl and Monnet (2007) present a model that investigates the role of private information about costs in a merger between a stock exchange and a settlement provider. They conclude that vertical silos can prevent efficient consolidation on a horizontal level. In contrast, Holthausen and Tapking (2007) and Rochet (2005) model the vertical relation between custodian banks and a CSD. In Holthausen and Tapking (2007) the CSD is input provider and competitor simultaneously. They show that the CSD leverages its monopoly power to compete for customers at the custodian level by raising it rivals' costs. Rochet (2005) asks whether a CSD should compete directly with custodian banks, or, in other words, should CSDs be allowed to integrate vertically with custodian banks. He concludes that the welfare effect of such a merger hinges on the trade-off between efficiency gains and lower competition on the custodian level due to the merger. This trade-off will be the center of attention in our paper as well. We, however, focus on a quite different aspect of the value chain which involves very different economic mechanisms.

The most relevant paper to our analysis is Tapking and Yang (2006). They analyze different industry settings in the sense of vertical or horizontal integration in a two-country model. They conclude that from a social perspective horizontal integration dominates vertical integration, which itself is better than no consolidation. We differ from their approach by focusing mainly on private incentives rather than pursuing a pure welfare analysis. In addition, we incorporate network effects as a major feature of the financial-security service industry. These network effects turn out to be a main driver of our analysis. Furthermore, we concentrate on the efficiency gain stemming from organizational restructuring that should be associated with the merger, whereas Tapking and Yang (2006) take only strategic effects in their analysis of vertical integration into account. That is, in contrast to their approach, we explicitly focus on the underlying driver of organizational change and 
its interaction with competition.

The paper is organized as follows. In the next section we outline the structure of the industry and then turn to the basic model in Section 3. On the basis of this, we discuss the incentives and consequences of vertical integration in Section 4. We thereby differentiate between a starting point in which any vertical integration is absent and one in which a certain financial-security service provider is already vertically integrated. With this distinction we aim to look into the potential cumulative effects as well as into situations in which history may matter. In Section 5, we compare vertical with horizontal integration. Section 6 discusses the endogenous listing decision and OTC trading as extensions of the model while Section 7 analyzes the implications of the emergence of Multilateral Trading Facilities, Algo-Trading, and TARGET2-Securities. The final section concludes.

\section{Functioning and structure of the industry}

Before turning to our model, we illustrate the basic structure of the industry by describing the functions of the securities transaction process as well as the main players in the market. The securities transaction process is basically characterized by three functions. The first function is the actual trading process, e.g., the matching of buyer and seller which usually takes place on the exchanges, alternative trading platforms, or via OverThe-Counter one-to-one trading. At this stage, an enormous network effect known as the liquidity effect is present. Traders favor exchanges on which other traders and therefore liquidity concentrate because it decreases the influence of their orders on the price. In addition, economies of scale and scope have an association with this process because the infrastructure can be used for many trades in the same as well as in other securities, leading to significant savings in fixed costs.

The second function is the clearing process. In this process, the bi-/multilateral obligations are calculated by the Clearing House, which in recent years has more frequently involved a Central Counterparty (CCP). The CCP takes the legal position of everyone's counterparts and therefore bears the risk of these participants. Usually it is able to net the trades and therefore bears less risk than the sum of the risk the original counterparts would otherwise have had to. Hence, again economies of scale and scope are present at this stage. The CCP are facing lower net risks if different securities or more of the same security are cleared in the particular CCP. Usually the clearing house is owned by the exchange.

The third function is the settlement process in which transactions are completed and the cash and securities are transferred. This service is usually offered by central security depositories (CSDs) that hold the securities and allow transactions by book entry. Again different systems can be used for different securities, and cash settlements might be netted 
that imply the presence of economies of scope at this stage. Beside CSDs also custodian banks can offer these services and take the role of an intermediary. They usually have an account at the main CSDs that allows their customers to trade securities kept at different CSDs (usually different countries) via one account.

Furthermore the CSDs offer safe-keeping for securities, e.g., the distribution of information by the security issuer, dividend flow, etc. The safe-keeping is needed to perform transactions but,unlike some other processes, it is not necessarily involved in every transaction.

If an entity owns the provider of all three transaction services we refer to this as a vertically integrated exchange or a silo.

\section{The basic model}

We consider a setting in which three exchanges or trading platforms $(i=A, B, C)$ compete with each other. Besides the three exchanges, there exist three central security depositories ( $j=A, B, C)$. Central security depositories may or may not be vertically integrated with the exchanges. Clearing services are provided by the trading platform and therefore are not considered separately. The costs to trade one unit of a security are identical across all three exchanges and denoted by $c^{T}$, the cost of settlement for CSD $i$ is $c_{i}^{S}$. A security that is listed on a particular exchange is kept in the respective CSD implying that a given security can be traded on different exchanges but is settled in only one CSD, giving that CSD monopoly power in this process. We assume perfect competition between custodian banks and therefore neglect them in our analysis. The total number of securities is normalized to one. The number of securities listed on either exchange is denoted by $n_{i}$.

Traders are uniformly distributed on the perimeter of a circle with a length equal to one and a density equal to one. All consumers demand inelastically one unit of each security listed on any of the three exchanges. The reservation price for all traders for trading and settlement services is denoted by $V$. This reservation price excludes the price of the security traded that we normalize for matters of simplicity to zero. Because we are only interested in the overall number of trades rather than the bilateral relation between seller and buyer, this reservation price is assumed to be identical for all traders. The three exchanges and the corresponding CSDs are symmetrically located on the perimeter of the circle at $0,1 / 3$ and $2 / 3$. Although CSDs can price discriminate between trades originated at different exchanges, exchanges cannot price discriminate between securities kept at different CSDs.

We denote the price of CSD $j$ for trades taking place on exchange $i$ by $p_{i j}^{S}$ while $p_{i}^{T}$ stands for the price of exchange $i$ charged for prices taking place on exchange $i$. Traders who have to pay both prices are assumed to expect the exchange in which the security is 
listed as being the more liquid one, hence, increasing the utility of traders trading on this platform by $k$. This is in line with the empirical observation that the liquidity of a stock is usually concentrated on the stock exchange where the company got its primary listing (see Halling, Pagano, Randl, and Zechner (2008)). In the following, we refer to $k$ as the liquidity parameter.

The further away a trader is located from the exchange he or she is actually trading on, the higher the disutility he or she realizes from the trade. Suppose a trader is located at $x$ and trades on exchange $i$. Let the closest distance between the trader and the exchange be defined as $g_{x}^{i}$. Then, the trader realizes a disutility of $t g_{x}^{i}$ with $t$ denoting the degree of differentiation across the exchanges. This disutility term reflects the idea that there are differences across exchanges that merely stem from locational differences, such as language, regulation, and the like. The more pronounced these differences are the larger $t$ is. We interpret this parameter $t$ as the degree of financial market integration. The less integrated financial markets, the larger $t$ is. We are aware that these differences usually take the form of discrete steps. Our continuous setup reflects the fact that these features are of different importance for different kind of traders (institutional, private, high-frequency). These different perception of the differences could be taken into account by a continuous function.

Therefore, we can state the utility of a trader being located at point $x$ on the perimeter of the circle who considers buying one unit of a security that is listed on exchange A as follows

$$
U_{x}^{A}= \begin{cases}V-p_{A}^{T}-p_{A A}^{S}+k-t g_{x}^{A} & \text { if trading takes place on exchange A } \\ V-p_{j}^{T}-p_{A j}^{S}-t g_{x}^{j} & \text { if trading takes place on exchange } j(j=B, C)\end{cases}
$$

In cases in which securities are listed on exchange $\mathrm{B}$ or $\mathrm{C}$ the corresponding utility functions apply.

Our analysis rests on the idea that the market is not fully covered, hence, leaving room for market coverage effects from vertical integration. Thereby, we also avoid that CSDs face a price-inelastic demand with all the special features of such a specific demand curve. Our no-full-coverage assumption is in line with the clearly observed home bias (see e.g. Tesar and Werner (2008)) by which investors focus more heavily on local securities, e.g., by concentrating on the (perceived) costs of price dispersion as well as the (perceived) informational advantages from buying local assets. In the absence of fully covered markets, investors do trade local securities overproportionally as compared to securities listed on other exchanges.

Furthermore, we impose a regularity assumption that states that the competition between exchanges takes place for the marginal trader being located between them, a standard assumption in the Salop-type model. Although, the first concept requires that 


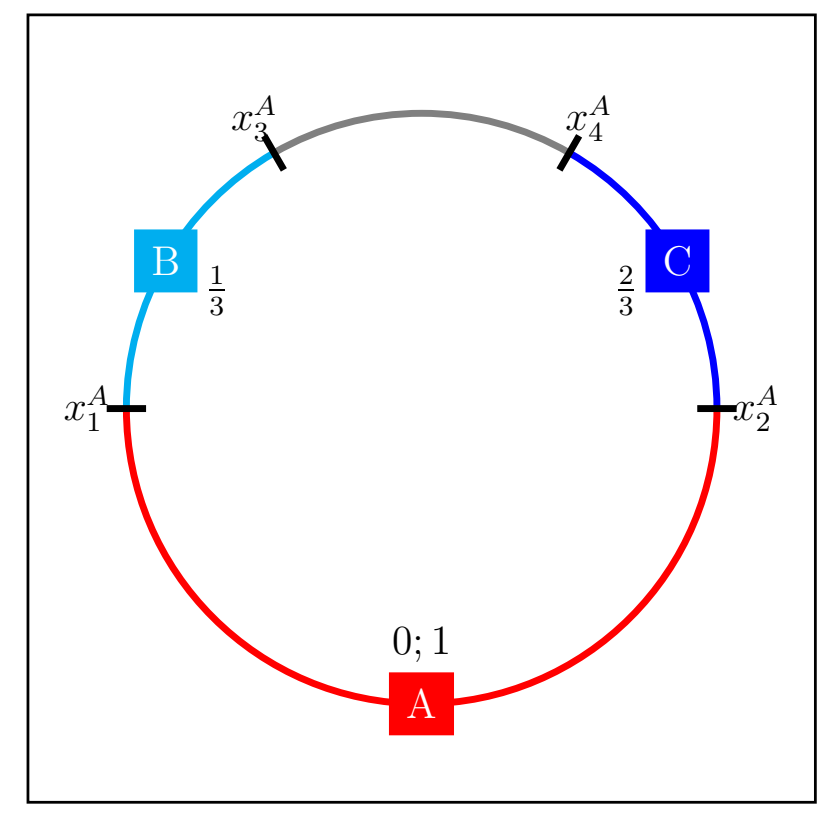

Figure 1: Industry structure of a security listed on A

transport costs are sufficiently large, the second one demands that the liquidity effect is not too large to avoid making the exchange on which the security is listed too strong.

More precisely, we impose:

\section{Assumption 1}

$$
t>k>\frac{1}{3} t
$$

\section{Assumption 2}

$$
\frac{11}{12} t>v>\frac{9}{8} t-\frac{5}{8} k
$$

with $v=V-c^{S}-c^{T}$ being the net social reservation price or the gains from the trade.

Therefore, we can derive the total demand of the trading platform on which the security is listed (say A) as the sum of the two marginal traders $\left(x_{1}^{A}\right.$ and $1-x_{2}^{A}$, see figure 1 ) being located between this platform and the two trading platforms with which it competes (B and $\mathrm{C}$ ). Total demand for the two remaining platforms stems from the sum of the respective demand accruing to these platforms when competing with platform $\mathrm{A}\left(\frac{1}{3}-x_{1}^{A}\right.$ for platform $\mathrm{B}$ and $x_{2}^{A}-\frac{2}{3}$ for platform $\mathrm{C}$ ) as well as the respective demand arising from the marginal traders on platforms $\mathrm{B}$ and $\mathrm{C}$ who are just indifferent between buying or not buying at all $\left(x_{3}^{A}-\frac{1}{3}\right.$ for platform $\mathrm{B}$ as well as $\frac{2}{3}-x_{4}^{A}$ for platform $\left.\mathrm{B}\right)$.

The assumptions stated above ensure that $0<x_{1}^{A}<1 / 3,2 / 3<x_{2}^{A}<1$ as well as $x_{3}^{A}<x_{4}^{A}$, i.e., the marginal traders for which platforms $\mathrm{A}$ and $\mathrm{B}$ as well as $\mathrm{A}$ and $\mathrm{C}$ compete is located strictly between them. The last inequality implies that the market is not fully covered. 
Deriving the marginal traders from the indifference conditions (of buying from a competing platform or buying not at all) yields the following demand functions:

$$
\begin{aligned}
& d_{A B}^{A}=x_{1}^{A}=\frac{p_{B}^{T}-p_{A}^{T}+p_{A B}^{S}-p_{A A}^{S}+k+\frac{1}{3} t}{2 t} \\
& d_{A C}^{A}=1-x_{2}^{A}=\frac{p_{C}^{T}-p_{A}^{T}+p_{A C}^{S}-p_{A A}^{S}+k+\frac{1}{3} t}{2 t} \\
& d_{B A}^{A}=\frac{1}{3}-x_{1}^{A}=\frac{p_{A}^{T}-p_{B}^{T}-p_{A B}^{S}+p_{A A}^{S}-k+\frac{1}{3} t}{2 t} \\
& d_{C A}^{A}=x_{2}^{A}-\frac{2}{3}=\frac{p_{A}^{T}-p_{C}^{T}-p_{A C}^{S}+p_{A A}^{S}-k+\frac{1}{3} t}{2 t} \\
& d_{B B}^{A}=x_{3}^{A}-\frac{1}{3}=\frac{V-p_{B}^{T}-p_{A B}^{S}}{t} \\
& d_{C C}^{A}=\frac{2}{3}-x_{4}^{A}=\frac{V-p_{C}^{T}-p_{A C}^{S}}{t},
\end{aligned}
$$

with $d_{i B}^{A}$ denoting the demand for trades on platform $i$ of securities listed on platform A when competing with platform B.

The total demand for trades on platform i for a security listed on platform A emerges as $d_{A}^{A}=d_{A B}^{A}+d_{A C}^{A}, d_{B}^{A}=d_{B A}^{A}+d_{B B}^{A}$, and $d_{C}^{A}=d_{C A}^{A}+d_{C C}^{A}$. In case trading for a security takes place on platforms $\mathrm{B}$ or $\mathrm{C}$, demand functions can be derived be simply replacing $\mathrm{A}$ with the respective platform on which the security is listed.

Hence we can state the profit function of the trading platforms as

$$
\pi_{i}^{T}=\left(n_{i} d_{i}^{i}+\sum_{i \neq j} n_{j} d_{i}^{j}\right)\left(p_{i}^{T}-c^{T}\right)
$$

as well as of the settlement platform of

$$
\pi_{i}^{S}=n_{i} \sum_{j}\left(p_{i j}-c^{S}\right) d_{j}^{i}
$$

\section{Vertical Integration in the Trading Industry}

We now turn to the analysis of vertical integration. Therefore, we start with a setting in which there is no vertical integration at all and one of the entities, say A, considers integrating trading and settlement. We refer to this as the stand-alone case. Later on, we contrast this with the decision to vertically integrate trading and settlement in A given that the other two entities are already vertically integrated. This comparison allows us to investigate potential cumulative effects of vertical integration: is vertical integration more or less likely if the other exchanges are already vertically integrated?

How do we depict vertical integration? We interpret vertical integration as a process which allows specific adjustments between the respective trading and settlement processes 
(e.g., establishing more efficient straight-through-processing) as well as faster coordination in the vertically integrated organization as compared to arm's length transactions. Vertical integration allows for specific investments between trading and settlement, most notably in the area of software and IT processes. In the absence of vertical integration, such specific investment might lead to severe hold-up problems between the two parties involved. Hence, our interpretation of vertical integration is on the one hand in line with the information we have gotten from many industry experts (which we received in the course of a number of interviews and discussions) and on the other hand conforms with the basic arguments from the theory of firm literature in the tradition of Grossman and Hart (1986).

\subsection{Private Incentives to integrate}

\subsubsection{The stand-alone case}

These specific investments tie trading platform A and settlement A together. However, this closer link between the two comes at a cost: it makes the interaction of trading platform A with the other two settlement organizations as well as the interaction of settlement in A with the two other trading platforms more costly because for them it becomes more difficult to route trades of securities not listed on platform A. Hence, vertical integration resembles a closed standard (with basically a (partially) incomplete technology). The efficiency of the standard increases but the interaction with agents outside the standard becomes more difficult (see e.g. Shy (2001)). We depict this concept as follows. With the vertical integration of settlement and trading in A, trades on A are settled at lower costs in A $\left(c_{A A}^{S}=c^{S}-y\right)$ but all cross-routings become more costly $\left(c_{A C}^{S}=c_{A B}^{S}=c_{C A}^{S}=c_{B A}^{S}=\right.$ $\left.c^{S}+y\right)$, with $y$ denoting the efficiency parameter associated with vertical integration. This entire process of vertical integration, which creates a more efficient link between settlement in A and trading in A but higher costs for the other links, is depicted in figure 2 .

We focus our analysis on these changes in efficiency in the interaction between exchanges and settlement organizations. Settlement and trading price setting in the vertically integrated organization are undertaken separately. That is, we neglect one benefit of vertical integration in our set-up in which settlement providers exert market power: the internalization of the external effect of the pricing decision of the trading entity on settlement (the double marginalization effect) as well as the other way round (settlement in A could charge prices in order to strategically affect the competition between the trading platforms). This is, from our point of view justified by two arguments. First, the implementation of an integrated decision process requires a proper transfer pricing system, which is often quite cumbersome. Second, the effects of the internalization pro- 
cess are quite obvious and very well investigated (see e.g. Tirole (1988), p. 174 ff.): they clearly favor vertical integration. Thereby, by neglecting this effect we bias against vertical integration, a fact which should be kept in mind when interpreting our results.

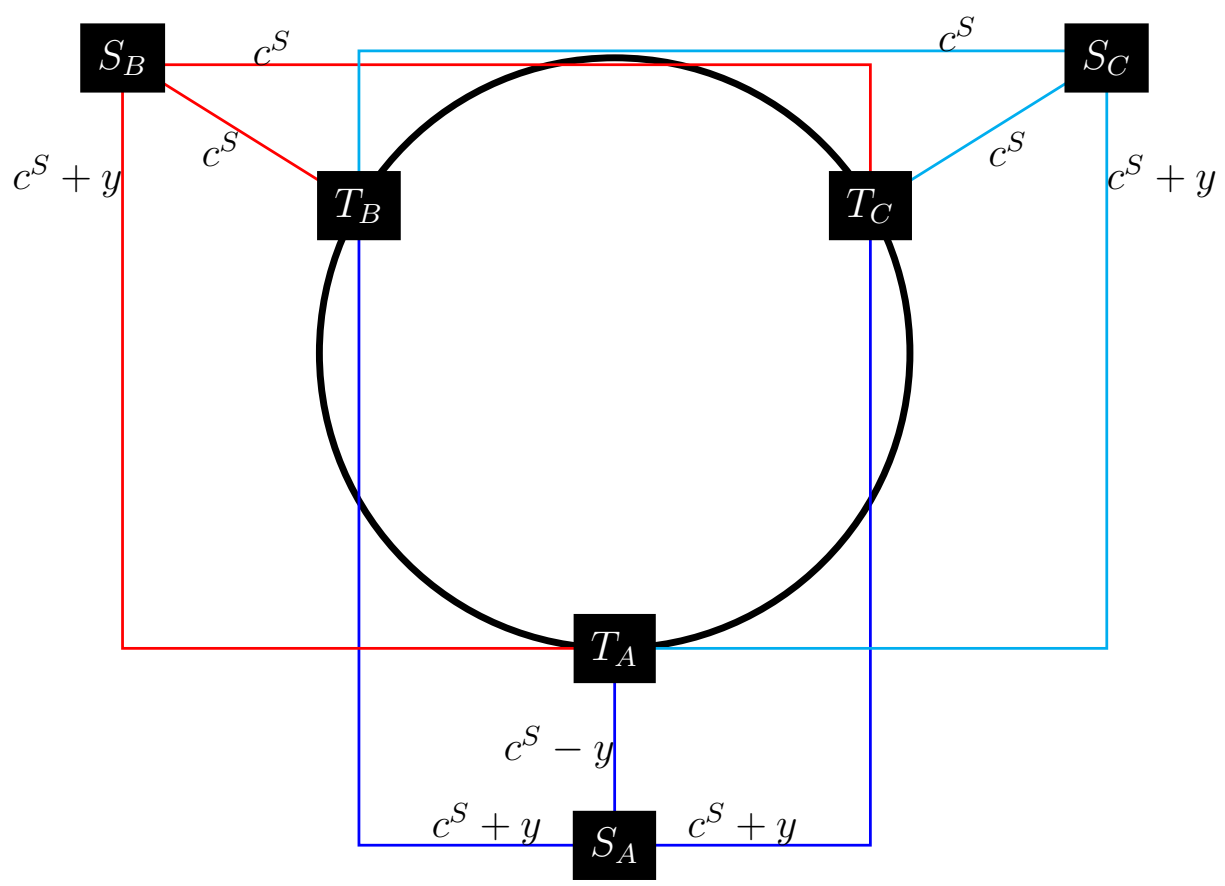

Figure 2: Vertical Integration

In order to avoid a more cumbersome technical discussion, we proceed as follows. We concentrate on the symmetric case in which an equal number of securities are listed on the three exchanges $\left(n_{i}=\frac{1}{3}\right)$. We investigate vertical integration and ask for the comparative static effects. For example, does an increase in the liquidity parameter $k$ increase or decrease the incentives for vertical integration?

For the symmetric case we derive the profit-maximizing trading and settlement prices for A (the prices for B and C can be stated correspondingly). This gives us the subsequent reaction functions for $i, j, l=\{A, B, C\}$ and $i \neq j \neq l$ (see the Appendix for the derivation)

$$
p_{i}^{T}=\frac{1}{2} c^{T}+\frac{1}{12} t+\frac{1}{4} V+\frac{1}{8}\left(p_{j}^{T}+p_{l}^{T}\right)-\frac{1}{8} p_{i i}^{S}-\frac{3}{16}\left(p_{j i}^{S}+p_{l i}^{S}\right)+\frac{1}{16}\left(p_{i j}^{S}+p_{i l}^{S}+p_{j j}^{S}+p_{l l}^{S}\right)
$$

and

$$
\begin{aligned}
& p_{i i}^{S}=\frac{1}{2} c_{i i}^{S}+\frac{1}{2} k+\frac{1}{6} t-\frac{1}{2} p_{i}^{T}+\frac{1}{4}\left(p_{j}^{T}+p_{l}^{T}\right)+\frac{1}{2}\left(p_{i j}^{S}+p_{i l}^{S}\right)-\frac{1}{4}\left(c_{i j}^{S}+c_{i l}^{S}\right) \\
& p_{i j}^{S}=\frac{1}{2} c_{i j}^{S}-\frac{1}{6} k+\frac{1}{18} t+\frac{1}{6} p_{i}^{T}-\frac{1}{2} p_{j}^{T}+\frac{1}{3} p_{i i}^{S}-\frac{1}{6} c_{i i}^{S}+\frac{1}{3} V
\end{aligned}
$$


It is important to note that corresponding prices are strategic substitutes (see Bulow, Geanakoplos, and Klemperer (1985) for the concept), i.e. $\partial p_{A}^{T} / \partial p_{j A}^{S}<0 \forall j$ and $\partial p_{A i}^{S} / \partial p_{i}^{T}<0 \forall i$. Hence, price increases by the settlement provider (to either trading platform) induce the trading platform to lower its price strategically. This mechanism will turn out to be important in our further analysis. While prices of corresponding upor downstream activities are strategic substitutes, the prices of the competitors on the trading level are strategic complements, i.e. $\partial p_{A}^{T} / \partial p_{j}^{T}>0 \forall j \neq i$. Increases in prices of the competitors lead to strategic price increases, i.e., reaction functions are upward sloping. This pattern depicts the conventional feature of the Salop model. Further, we should note that changes in the prices charged by settlement providers to trading platforms $\mathrm{B}$ and $\mathrm{C}$ lead to a price increase on trading platform A, i.e. $\partial p_{A}^{T} / \partial p_{i j}^{S}<0 \forall i$ and $j=B, C$.

On the settlement level, the CSDs do not compete with each other at all but the prices set to the different trading levels interact with each other. All these interactions are decisive in our analysis of the vertical integration process.

Overall, we have twelve first order conditions ( 3 trading prices and 1 settlement prices for each trading platform) that we need to solve simultaneously. By doing this, we find (all proofs are delegated to the Appendix):

Lemma 1 Vertical integration leads to a decrease in all trading prices. This effect is less pronounced in the integrated exchange $A$ as compared to the non-integrated exchanges $B$ and $C$. With settlement, only the services provided via the direct, more efficient link become cheaper, while all other settlement services become more expensive.

The somewhat surprising result of the effect of vertical integration on relative trading prices stems from the fact that direct trading and settlement prices are strategic substitutes (see Eqs.(10)-(12)): higher settlement prices lead trading platforms to reduce their trading prices. Hence, platforms $\mathrm{B}$ and $\mathrm{C}$ that face higher settlement prices for securities listed on A have an incentive to reduce their price. Given that trading prices are strategic complements this triggers a reduction in A's trading price. This is reinforced by the marginal weighted increase in settlement prices that leads, given that they are strategic substitutes to A's trading price, to a decrease in A's trading price as well.

A further channel through which vertical integration affects the payoffs of all agents is the impact of vertical integration on traders' behavior and market coverage. We find:

\section{Lemma 2}

(i) Market coverage of securities listed on all platforms decrease.

(ii) The vertically integrated platform $A$ wins trades vis-a-vis platforms $B$ and $C$ in securities listed on $A$ while losing trades for securities listed on $B$ and $C$. 
The decreased coverage of the market (part (i) of the Lemma) stems from the fact that the sum of trading and settlement prices, which traders located between $\mathrm{B}$ and $\mathrm{C}$ have to pay, increases. Part (ii) of the above Lemma is due to the fact that, via vertical integration, cross-platform links become more costly; hence making the respective "home" platform more competitive.

By using our findings on prices and quantities allows us (see the Appendix) to derive the profit difference of the sum of the profits in trading and settlement in A:

$$
\Delta\left(\pi_{A}^{S}+\pi_{A}^{T}\right)=y \frac{198900 k+8476 t-173472 v+278409 y}{608400 t} \equiv y \Gamma
$$

Using this expression allows us to compute comparative static effects. We find:

Proposition 1 Vertical integration is more likely to pay off if

- demand for liquidity is high $(\partial \Gamma / \partial k>0)$,

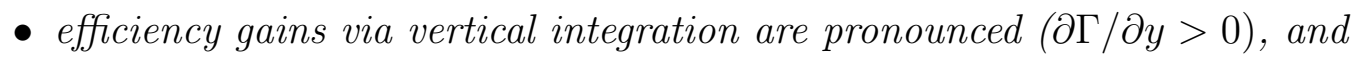

- the gains from trade are low $(\partial \Gamma / \partial v<0)$.

- The effect of more integrated financial markets is ambiguous: if the liquidity effect $k$ and/or the efficiency gains are relatively large compared to $v$, a higher degree of integration increases the profitability of vertical integration and vice versa for a relatively small $k$ and $y$.

The intuition behind these findings is as follows. The more liquidity matters, the higher the share of trades kept safe in CSD A being traded on platform A using the efficient link. The more important the liquidity effect is, the larger the share of trades of a particular security taking place on the platform on which this particular security is listed and kept safe, respectively. Hence, the absolute and relative cost advantage of vertical integration is most pronounced.

The fact that more pronounced efficiency gains make vertical integration more attractive is due to the circumstance that trades on platform A take place relatively more often with securities listed on platform A relative to those listed on platforms B and C. Hence, absolutely more trades are settled via the efficient link in our symmetric setting. If this link becomes even more efficient (larger $y$ ), then it makes vertical integration even more attractive.

Higher gains from trade lead to more trades on B and $\mathrm{C}$ of securities kept safe in $\mathrm{A}$ and vice versa. These trades are settled through the inefficient link after vertical integration. Hence, since these trades increase absolutely and relatively with higher gains from trade, this makes vertical integration less attractive. 
The effect of less integrated financial markets (higher $t$ ) is ambiguous and depends on $k$ and $v$. If the liquidity effect $k$ is relatively large compared to the gains from trade, a higher $t$ decreases the profitability of vertical integration $(\partial \Gamma / \partial t>0)$ and vice versa. The intuition behind this is as follows. Assume for the beginning small efficiency gains $(y \rightarrow 0)$. The demand via the inefficient link, either from CSD A to exchange B/C or from exchange A to CSD B/C, increases in $v$ (more trades from the backyard) but decreases in $k$ (less trades in competition area with home market). In contrast, the demand via the efficient link is independent of $v$ but increases in $k$. An increasing $t$ now reduces the influence of $k$ as well as of $v$. Therefore, if $k$ is compared to $v$ relatively large, an increasing $t$ increases the demand via the inefficient links (protection from the liquidity disadvantage), but decreases it if $k$ is relatively small (loss of consumer to the backyards dominates). In contrast, the demand via the efficient link always decreases in $t$. Summing up these effects, relatively more trades are processed over the inefficient link and the gains of integration decrease while the differentiation increases if $k$ is relatively large. Furthermore, the impact of the size of the efficiency gain $y$ has the same direction as $k ; y$ influences the number of additional trades via the efficient link. The larger $t$, the smaller is the effect of this competitive advantage.

A remaining, but important issue is whether a positive profit difference (i.e. positive $\Gamma)$ is indeed feasible. In addition, we now address the question how vertical integration, if it is indeed attractive, affects the payoffs of the other agents (i.e., profits for the other platform, consumer surplus, as well as overall welfare).

Figure 3 displays Eq.(13), as well as our Assumptions 1 and 2 on the parameters (the grey area is not compatible with these assumptions), in $\frac{k}{t}-\frac{v}{t}$ space. Besides reflecting the results of Proposition 1 once again, it clearly shows that vertical integration can indeed pay off. The white range in the figure displays the parameter combinations that are not only feasible but also increase the sum of profits of A with vertical integration even if the marginal efficiency effect is evaluated at $y=0 .{ }^{4}$

\footnotetext{
${ }^{4}$ An obvious limitation to our analysis so far is our symmetry assumption. We argue, however, that relaxing this assumption does not change our qualitative analysis so far. We do this by proving that locally (i.e., at $n_{A}=1 / 3$ ) the profit difference is always strictly increasing in $n_{A}$. Taking the first order derivative of the profit difference with respect to $n_{A}$ gives us (see the Appendix for a derivation of this):

$$
\frac{\partial \Delta\left(\pi_{A}^{S}+\pi_{A}^{T}\right)_{n_{A}=1 / 3}}{\partial n_{A}}=y \frac{2405520 k+785876 t-47892 v+2965353 y}{5272800 t}>0 .
$$

The positive sign of this expression follows from our assumptions stated above.

Investigating this relation not only locally but for different $n_{A}$ we are unable to provide a general proof, but can argue on the basis of a large number of numerical exercises that the sign of Eq. (4) when mapped onto the size of platform A (i.e. $n_{A}$ ) is indeed positive implying a rising incentive to vertically integrate with size. This is quite reasonable. The larger a trading platform is, ie., the more securities are listed on it, the more (less) trades are settled via the (in-) efficient link, hence making vertical integration more attractive.
} 


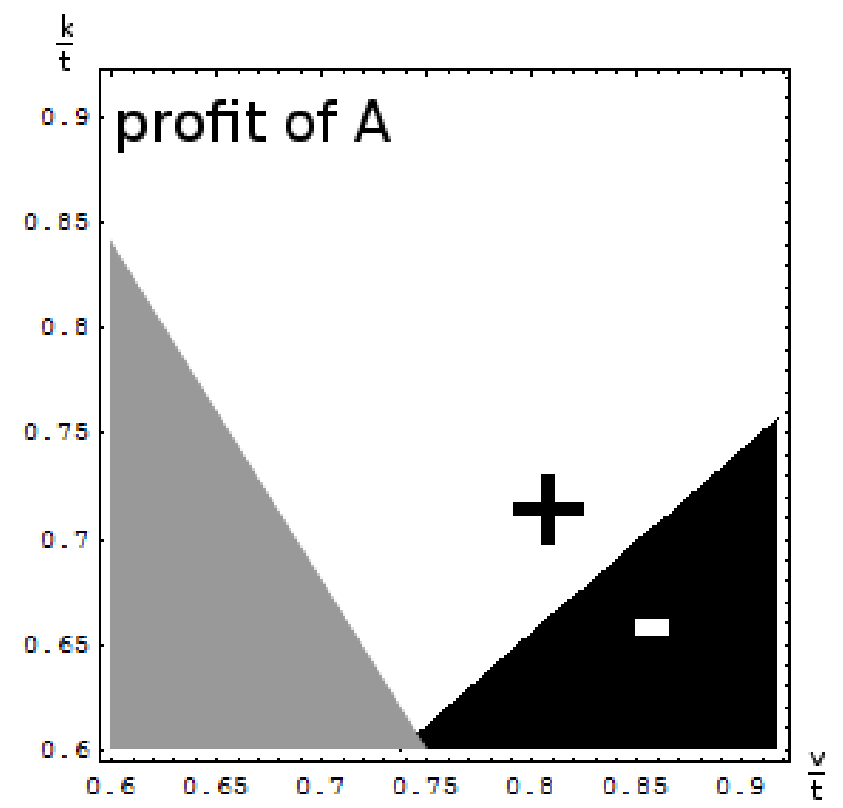

Figure 3: Effect of vertical integration on profit of A

As a next step, we consider the effects of the vertical integration of platform $\mathrm{A}$ on the other players in the market. Thereby, we are able to gain insights into the potential externalities vertical integration imposes on other market participants. These other market participants are the competitors of platform A (trading and settlement platforms B and C) as well as the traders in the markets. We pursue our analysis in this order.

The corresponding profit difference for platforms $\mathrm{B}$ and $\mathrm{C}$ reads as:

$$
\Delta\left(\pi_{q}^{S}+\pi_{q}^{T}\right)=y \frac{105300 k-36868 t-215904 v+172233 y}{1216800 t} .
$$

Given our assumptions for the feasible parameter range (which imply that $v>0.5 t>$ $0.5 k)$, it immediately becomes clear that the profit differential is always negative for sufficiently small efficiency gains (e.g., $y$ approaching zero). Despite the fact that B and $\mathrm{C}$ gain via less intense competition, they loose traders with respect to securities listed on platform A to trading platform A and to the non-trading camp. Overall this leads to a decrease in profits. Hence, A's vertical integration decision imposes a negative externality on A's competitors.

Computing the difference effect of vertical integration on the well-being of traders yields a surplus for traders (see the Appendix for details of the computation)

$$
\Delta \text { TradersSurplus }=y \frac{152100 k+7436 t-129792 v+203289 y}{608400 t} .
$$

Pretty much the same mechanisms apply as with Proposition 1. A more pronounced liquidity effect and a lower net social reservation price lead to relatively more trades via 
the efficient link. Securities listed on exchange A are more often traded on this platform. The traders gain via lower prices through which settlement providers channel efficiency gains to traders. Figure 4 shows that traders - in sum - may indeed gain from vertical integration absolutely. This gain implies that in our symmetric setting the gains of the traders who benefit from the standardization of the vertically integrated exchange (i.e., those having a preference to trade on exchange A) outweigh the losses of traders who have a preference for other exchanges.

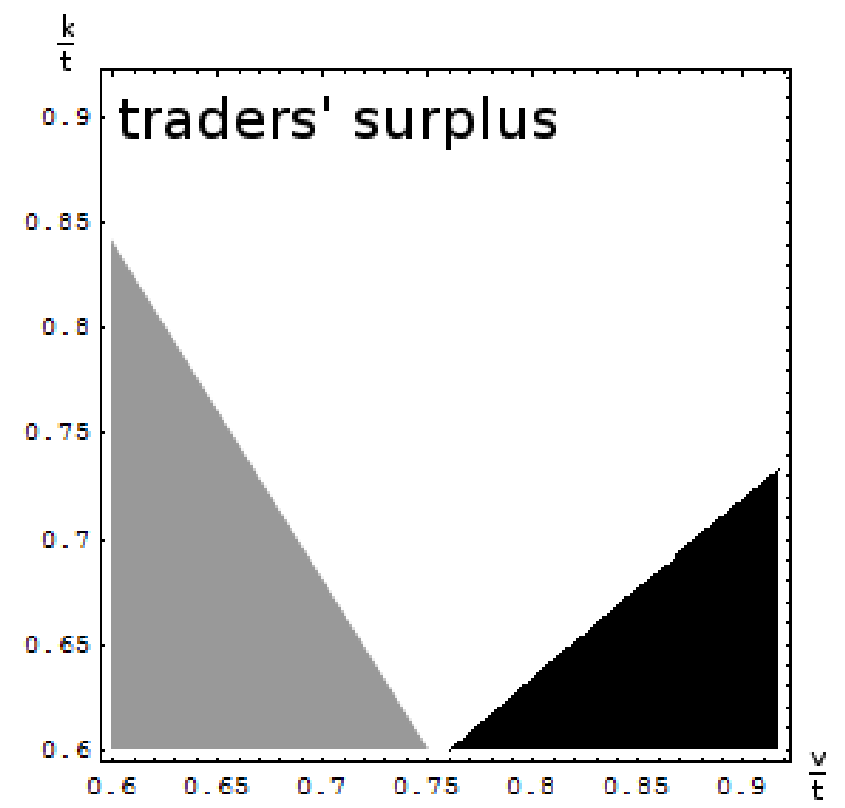

Figure 4: Effect of vertical integration on traders' surplus

\subsubsection{Vertical integration if everybody else is}

One of the main aims of this paper is to shed light on industry dynamics and the evolution of the trading and settlement industry. Against this background, it is important to investigate to what extent the incentives to integrate vertically hinge on the existing industry structure. Or in a nutshell: is vertical integration more or less attractive if competitors are already integrated or not?

We start out by looking into the incentives for A to vertically integrate if one of the other platforms (say B) is already vertically integrated. This situation implies that the already vertically integrated platform not only has established an efficient link in B but has build up inefficient links with $\mathrm{A}$ and $\mathrm{C}$. Hence, the vertical integration process only adds an efficient link to $\mathrm{A}$ and an inefficient to $\mathrm{C}$ (rather than with $\mathrm{B}$ and $\mathrm{C}$ as in our previous). Somewhat surprisingly, we find: 


\section{Proposition 2}

(i) Vertical integration is privately more attractive if all other platforms are already vertically integrated as compared to a situation in which the other platforms are not yet vertically integrated.

(ii) There might exist a coordination problem: if one platform vertically integrates all others have an incentive to follow despite the fact that platform profits may be lower in the new equilibrium.

The intuitive explanation behind part (i) of Proposition 2 can be best understood by noting that the integration of one platform (say B) implies that the benefits for A stemming from its own integration increase. After the integration of B, A faces a competitor with an efficient link; hence, making it more attractive to establish an efficient link on its own as well. Furthermore, after B's integration, there is already an inefficient link between $\mathrm{A}$ and $\mathrm{B}$ thereby eliminating these additional costs for A's integration. Taking these two effects together makes A's integration more attractive after B's integration compared to the situation in which A goes for a head start with respect to vertical integration.

Obviously, given $\mathrm{A}$ and $\mathrm{B}$ decide to integrate, $\mathrm{C}$ follows. Therefore, we observe a bandwagon effect. If one exchange decides to integrate, the others follow. This effect also means that, say for historical reasons the exchange and the respective CSD are integrated in country A, the probability that the financial-security service providers in country B and $\mathrm{C}$ decide to do the same is high.

This bandwagon effect might be associated with a coordination problem. In other words, we find situations where it is advantageous for one exchange to integrate but then the others follow and in the end they are all worse off. Graphically, we can illustrate these parameter constellations in figure 5 where the dark grey shaded area is the parameter region where we observe a prisoner's dilemma.

This potentially excessive degree of vertical integration (from the viewpoint of the platforms only) stems from the fact that vertical integration comes with negative externalities imposed on the other platforms as we have argued above.

\subsection{Welfare consequences of vertical integration}

In the next step, we aim to investigate the overall welfare consequences of vertical integration. As before, we distinguish between two settings. In the first one, only platform $\mathrm{A}$ is vertically integrated at the end (stand-alone case). In the second one, all platforms are integrated at the end (full integration). 


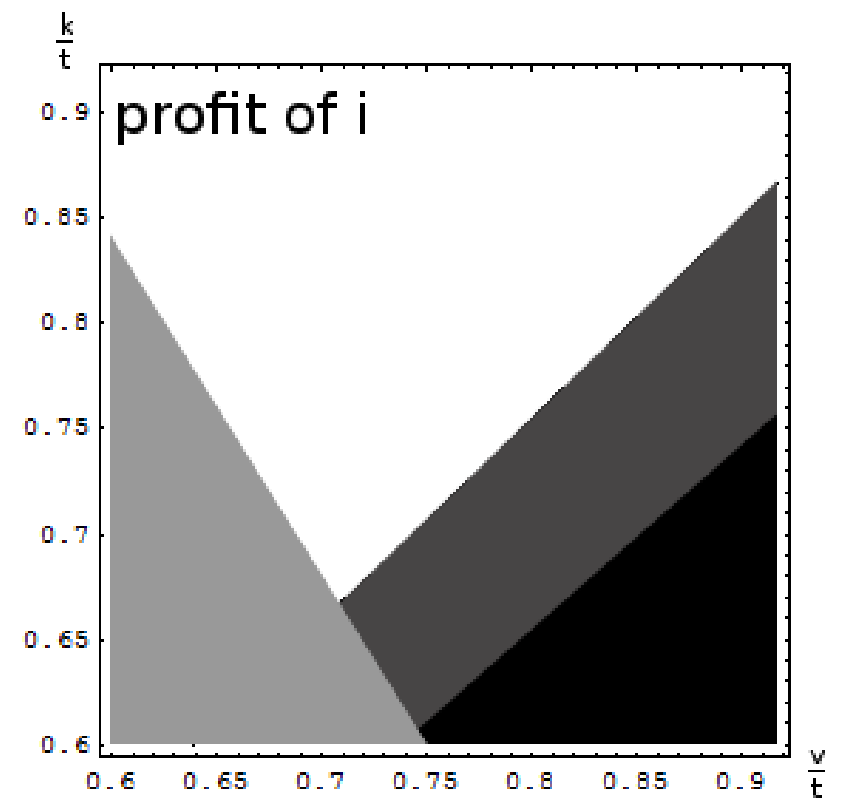

Figure 5: Effect of vertical integration of all financial-security service provider on profits

\subsubsection{Stand-alone case}

Our discussion above indicates that moving platform A towards vertical integration when the others are not integrated imposes a negative externality on A's competitors and a positive one on traders.

The overall difference in welfare (i.e., taking the sum of all profits and trader surplus) in the stand-alone case amounts to

$$
\Delta \text { Welfare }=y \frac{456300 k-20956 t-519168 v+653931 y}{608400 t} .
$$

We find

Proposition 3 With stand-alone integration the negative externality on competing platforms exceeds the positive impact on traders, hence, leading to potentially excessive vertical integration.

Because platform A does not internalize the impact of its integration decisions, it has, in total, much stronger incentives to vertically integrate than a social planner.

Figure 6 illustrates this finding. It shows that vertical integration might improve overall welfare in our symmetric setting. But the comparison with figure 3 discloses that there exists a parameter region in which private and social incentives diverge. This parameter region is characterized by intermediate levels of the liquidity parameter and the gains from trade. 


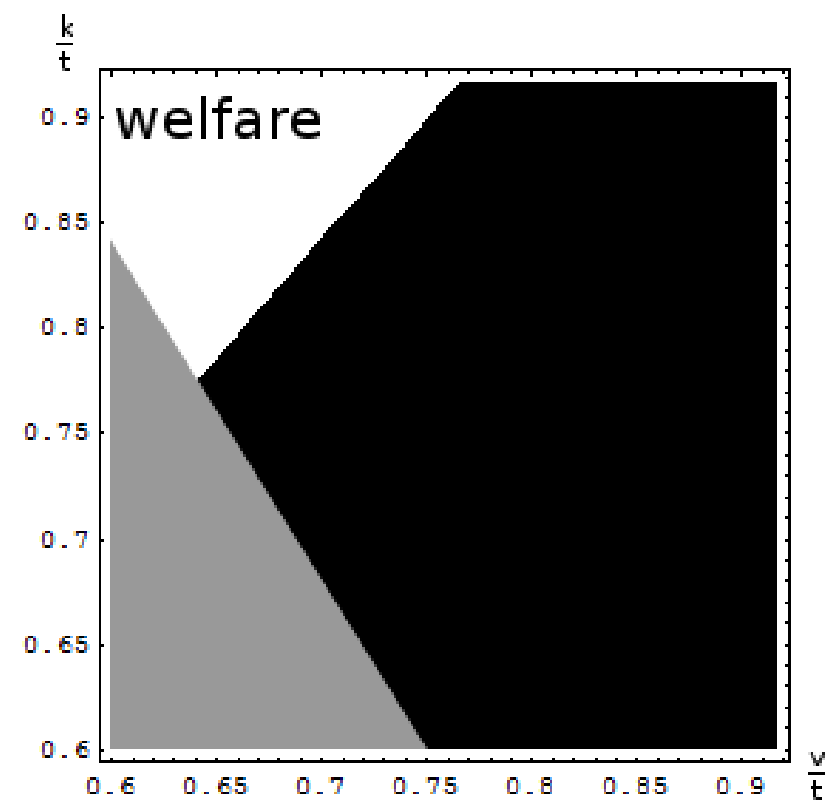

Figure 6: Effect of vertical integration on total welfare

\subsubsection{Full integration}

This excessive integration scenario is caused by the negative externality effect imposed by platform A on other exchanges in the stand-alone case. The negative externality itself stems from the fact that vertical integration in the stand-alone case reduces costs for A but increases those for B and C. However, if these other two platforms are already vertically integrated, this latter effect is absent and only the cost-reducing effect that affects B and C's profits exists. Hence, negative externalities are clearly lower. In turn, because there is only a cost-reducing effect, the positive externality on traders is higher. Therefore, one might conjecture, that the positive externality dominates the negative one, leading to net positive externalities and therefore to too few incentives to vertically integrate.

We therefore compare situations with or without full-scale integration from a welfare as well as from a private point-of-view.

The overall welfare effect is expressed by

$$
\Delta W \text { elfare }=y \frac{225 k+11 t-192 v+321 y}{150 t} .
$$

This effect shows us that, compared to the situation of A-integration for a larger set of parameters, welfare increases (see Eq. (7)), thereby confirming our above conjecture among other things.

In order to find out whether private incentives to start the process of vertical integration are in line with the social ones to achieve full integration, we have to compare Eqs. 


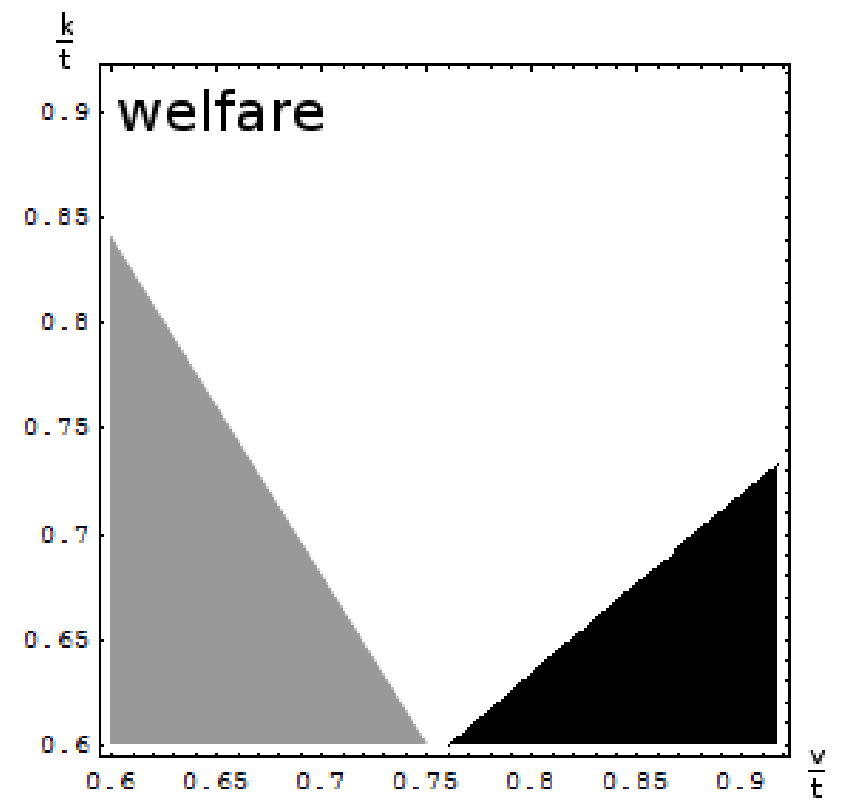

Figure 7: Effect of vertical integration of all financial-security service provider on welfare

(13) and (17) with each other (or in graphical terms figures 7 and 3). ${ }^{5}$

By doing so, we find:

Proposition 4 While the process towards full integration via the bandwagon effect might be harmful to platforms, this integration process leading to full integration is beneficial for society.

\section{Horizontal integration}

Given network economies as well as economies of scale and scope, horizontal integration is an alternative to vertical integration that is intensively and hotly discussed in the financial press (see Economist (2006)). Therefore, we consider horizontal integration for its own sake but also in comparison to vertical integration. In our framework, horizontal integration of trading platforms for matters of the exploitation of liquidity and network effects leads to a joint trading platform that eliminates the limited access of certain traders to certain stocks and, thus, to the coverage gap in our base model. In a nutshell, horizontal integration of trading platforms changes the market structure at the trading level and, therefore, the entire model structure, which makes a comparison with vertical integration infeasible. In order to avoid this problem, we consider horizontal integration at the settlement level. At

\footnotetext{
${ }^{5}$ Due to the bandwagon effect, we know that, if starting the vertical integration process on a standalone basis, it will finally lead to full integration. Therefore, the private incentives as expressed in Eq. (13) are the right measure of comparison.
} 
this level, horizontal integration leaves market structure unchanged, and the settlement providers stay in their monopolistic situation.

To capture the concept of network effects as well as of economies of scope at the clearing and settlement level, we model horizontal integration as cost savings, $b \cdot y(0<b<1)$, of all settlement provider. So, while trading platforms' costs amount to $c^{T}$, the costs of all settlement provider are $c^{S}-b y$.

Given that the monopolistic settlement provider all experience identical cost savings, their monopolistic profits increase. Since there are only gains but no costs to horizontal integration, this is quite clear. Rather than introducing the costs of integration as a countervailing balance we pursue what we consider a much more interesting alternative: to compare the incentives to integrate horizontally with those of vertical integration.

In a first step we compare, from the viewpoint of individual firms, the gains from horizontal integration with the potential gains from vertical integration in one platform given that all other platforms are vertically nonintegrated. This basically depicts a situation with the very same starting point in which a settlement provider can either decide to vertically integrate with the corresponding trading platform or join forces with the other settlement providers to integrate horizontally. Since there is no reason in our model to stop short of integrating all three settlement providers, we equate horizontal integration with the integration of all three rather than only two settlement providers, a procedure which affects our comparison quantitatively but not qualitatively. Furthermore, given that our previous discussion has shown that stand-alone vertical integration requires higher incentives than the vertical integration decision where others are already vertically integrated, this comparison allows a prediction on the final equilibrium starting from a situation of complete nonintegration.

In a second step we compare the private incentives for horizontal or vertical integration with the optimal decision rule in which the central planner compares horizontal integration with full-sized vertical integration. With this second step, we examine whether it might be feasible for the market solution to end up in a bad equilibrium due to a coordination problem with settlement and trading platforms.

\subsection{Horizontal vs. Vertical Integration - Private Incentives}

By using the profit-maximizing prices together with the demand functions in the profit functions allows us to derive the following profit difference for all settlement providers, i.e., the sum of settlement providers' profits after horizontal integration minus the one before integration (see the Appendix for details):

$$
\Delta\left(\pi_{A}^{s}+\pi_{B}^{s}+\pi_{C}^{s}\right)=8 b y \frac{2 t+6 v+3 b y}{75 t} .
$$


Subtracting this expression from the profit difference resulting from vertical integration (see Eq. (13)) yields

$$
\Sigma_{\text {Profits }}=y \frac{198900 k+8476 t-173472 v+278409 y-64896 b(2 t+6 v+3 b y)}{608400 t} .
$$

We interpret this expression as the differential incentives for one settlement provider to choose horizontal rather than vertical integration.

Checking for the sign of Eq. (19) and solving for the critical $b$, which just leads to indifference between vertical and horizontal integration (at $y=0$ ) yields

$$
b^{*}=\frac{198900 k+8476 t-173472 v}{64896(2 t+6 v)} .
$$

Given our assumptions, $b^{*}$ is always smaller than one, which is a rather intuitive result. With $b=1$, all settlement providers face efficient links with horizontal integration; but, with vertical integration, the integrating platform has to tradeoff the direct efficient link for the indirect inefficient link. The cost disadvantage of the inefficient link outweighes the competitive advantage that the other settlement providers have and deters them from relying on the inefficient links as well. Overall, this implies that with $b=1$ horizontal integration dominates vertical integration.

We find:

Proposition 5 Private Perspective: Vertical integration (on a stand-alone basis) becomes more attractive for a single platform relative to horizontal integration if

- the liquidity effect is more pronounced $\left(\partial b^{*} / \partial k>0\right)$,

- and the gains of trade becomes larger $\left(\partial b^{*} / \partial v>0\right)$.

- The effect of more closely integrated financial markets is ambiguous $\left(\partial b^{*} / \partial t>0\right.$ for $v>k$ and vice versa).

The intuition is rather similar to Proposition 1. With vertical integration, a more pronounced liquidity effect shifts more trades into the settlement via the efficient link. This shift has a positive effect on the profits of the integrated platform making vertical integration relative to horizontal integration more attractive. In contrast, with horizontal integration all settlement links become cheaper to the same extent. Hence, a change in the market shares of the different trading platforms does not affect profits in the case of horizontal integration, which leaves no room for an effect of $k$ on the incentive to horizontally integrate. Compared to Proposition 1, horizontal integration as an alternative adds an additional disadvantage to vertical integration that grows with the size of the gains from trades. 
The effect of the financial market-integration parameter $t$ is ambiguous. A lower degree of integration (larger $t$ ) decreases the profitability of horizontal integration, because less additional trader are won. In contrast, we know from Proposition 1, that if $k$ is relatively large an increasing $t$ decreases the profitability of vertical integration. In sum, we still get the ambiguity, with a slightly different parameter condition. The liquidity effect needs to be larger compared to Proposition 1 to receive the decreasing pattern of $b^{*}$.

\subsection{Horizontal vs. Vertical Integration - Social Incentives}

We now turn to the evaluation of different industry equilibriums (with either full horizontal or full vertical integration) from a welfare point of view, and the private incentives to reach these equilibriums (remember: if a financial-security service provider in one country decides to integrate the others will follow). We especially examine whether there is a potential coordination effect in the sense that it is socially feasible to have full-scale vertical integration when private incentives stand in the way of a headstart such that initial horizontal integration is preferred despite the fact that in the end the latter is socially dominant.

The private incentives to reach either of the two industry equilibriums has been investigated above (see Eq. (20)). Hence, we need to evaluate full-scale vertical integration (embracing all three platforms) and horizontal integration from a welfare point of view. Computing the relative gains in welfare accruing from full-scale vertical versus horizontal integration gives us:

$$
\Sigma_{W e l f a r e}=y \frac{225 k+11 t-192 v+321 y-32 b(2 t+6 v+3 b y)}{150 t}
$$

which, if positive, implies that vertical integration dominates horizontal integration from a welfare point of view.

Evaluated at $y=0$ this yields the critical social $b_{f s}^{*}$ :

$$
b_{f s}^{*}=\frac{225 k+11 t-192 v}{32(2 t+6 v)} .
$$

As the next step, we compare the private incentives for reaching either equilibrium with the relative advantages of either equilibrium from a social point of view. When comparing $b^{*}$ with $b_{f s}^{*}$ we find

$$
\operatorname{sign}\left(b_{f s}^{*}-b^{*}\right)=\operatorname{sign} \quad\left(\frac{257400 k+13832 t-215905 v}{64896(2 t+6 v)}\right) .
$$

Figure 5.2 depicts these differences and distinguishes between the two cases in which these differences are positive (lower part) or negative (upper part). 
Excessive horizontal integration
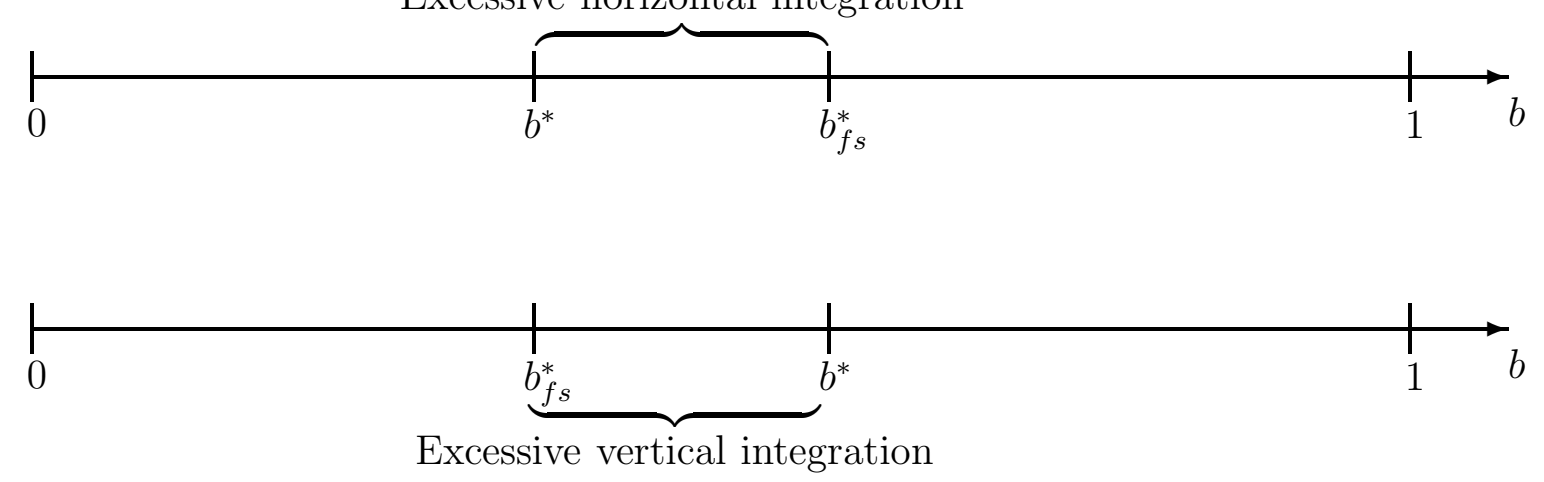

Figure 8: Private vs social incentives

Hence, we find:

Proposition 6 Social vs private perspective: With strong (weak) liquidity effects and weak (strong) social net reservation prices, the industry might end up in a bad equilibrium in which settlement providers are horizontally (vertically) integrated.

To better understand the economic intuition behind this result it is important to notice that vertical integration as well as horizontal integration imposes an positive externality on traders. The externality of vertical integration increases with the importance of liquidity, and more important it increases overproportionally to the profit difference of an individual CSD/exchange. Strong liquidity effects imply that a relatively large share of trades take place via the efficient link while relatively few trades take place via the inefficient link. Hence, traders benefit relatively more, while the other firms loose relatively less. The opposite is true for the gains from trade, the externality decreases with gains overproportionally to the individual profit. In contrast, the private and social incentives for horizontal integration increase (decrease) proportional to each other. In sum, a social planer demands a larger cost saving from horizontal integration than an individual CSD if the importance of liquidity is high. Less integrated financial markets decrease the importance of the liquidity as well as of the gains from trade. It therefore depends on the relative importance of these parameters. 


\section{$6 \quad$ Extensions}

\subsection{Endogenous Listings}

So far our analysis has been undertaken against the background of a given distribution of listings of securities across the trading platforms. We proceed by thinking about endogenizing the listings of securities. In order to endogenize the listing decision, it is crucial to think about the objective function behind this listing decision. There are two obvious factors determining the listing decision, the first one being the costs of the listing consisting of direct ones (paid to the trading platform) and indirect ones (costs of reporting and disclosing information and the like). The second factor, which is potentially of much more importance for the listing decision is the degree of access to capital markets. This latter effect is strongly affected by the size and liquidity of the respective trading platform. Firms setting up a listing are especially interested in reaching a wide range of potential investors for a security. This range provides them with immediate investors in the primary market with a broader subsequent market making the initial investment more attractive. Hence, initial investors are willing to pay higher prices leading to a lower degree of underpricing. Furthermore, a broader set of investors facilitates subsequent (seasoned) offerings.

In our model, the number of investors reached equals the market coverage. Thus, we consider the listing decision as the outcome of a cost-benefit trade-off in which the price paid is contrasted with the gain that accrues from the investors for its security that the company/organization listing reaches. We therefore depict the objective function as

$$
\Pi_{f}=a * \text { coverage }-p_{L}^{T}-p_{L}^{S}-l_{f}
$$

with coverage denoting the market reach of the security, and $p_{L}^{i}$ the price to be be paid to the trading/settlement platform. Parameter $a$ stands for the importance of the coverage and $l_{f}$ is a differentiation parameter of a firm $f$. Such a differentiation, which seems to be relevant as it is rather uncommon that firms choose a primary listing abroad (at least

for firms in developed countries), correspond to $t$ of the former sections and therefore decreases also with more integrated financial markets.

One may think of the listing decision as a two-stage game. In stage 1, exchanges set listing fees and firms decide about their listing venue. In stage 2, exchanges and CSDs set their trading and settlement fees and traders decide if and where to trade. Reasoning backwards shows two results. First, listings are very important for exchanges and CSDs since they are absolutely necessary for CSD business and because they offer a competitive advantage via the liquidity (or expectations) effect for exchanges. This effect should lead to an incentive for the exchange to "buy in" this market side and result in rather "low" listing fees. 
In addition, firms anticipate their market coverage on the respective trading venue and a comparably smaller potential coverage can be offset by lower listing fees. Therefore, since vertical integration affects the market coverage negatively, an integrated exchange has to reduce $p_{L}^{i}$ in order to avoid loosing listed securities. This observation adds an additional disadvantage to vertical integration from an exchange perspective that is ceteris paribus larger the higher the weight of coverage, i.e., the larger $a$. In contrast, the disadvantage is smaller the lower the degree of financial market integration from the view of the firms, i.e., the larger $l_{f}$.

Table 1 compares the listing and admission fees of Deutsche Börse as the European exchange with the highest degree of vertical integration and the LSE as the one with the lowest degree. These fees can be interpreted as an initial rough indication towards our hypothesis that vertically integrated exchanges indeed demand lower listing fees.

\begin{tabular}{lcc}
\hline & Deutsche Börse & London Stock Exchange \\
\hline Admission Fees & $750-5,500 €$ & $9,508-230,565 €$ \\
Listing Fees & $5,000-10,000 €$ & $5,211-19,453 €$ \\
\hline \hline
\end{tabular}

Table 1: Admission and Listing Fees for ordinary shares depending on market segment and market cap. (Source: Kaserer and Schiereck (2008))

\subsection{OTC Trading}

The alternative to trading on exchanges is bilateral OTC trading. In OTC transactions traders privately negotiate the individual conditions of a trade. Because the terms and conditions are private information, the liquidity effect becomes irrelevant. The advantage of OTC compared to trades on exchanges is, on the one hand, the possibility to trade non-standardized contracts that can be tailored to the needs of the trading partners. On the other hand, OTC trading fails to keep the trade secret implying that it has no impact on the market price and hence on the value of the trading positions. The obvious disadvantage stems from the fact that there is less liquidity in the market requiring a need for a trading partner.

OTC trading influences the integration decision of traditional exchanges via two potential mechanisms. First, assume OTC trading is not a substitute for trading on exchanges. In order to settle OTC trades, traders also need a link to the corresponding CSD. In case of a vertically integrated CSD, such a link is out of the vertical system and thus "inefficient". Therefore the larger OTC markets a larger fraction of trades is settled via the inefficient link. If demand elasticity is finite, the integrated exchange is not able to transfer the increased costs fully to traders, which implies a reduction in the exchange's profits. Hence, the larger the OTC market, the less attractive vertical integration is for 
the exchanges as well as for the welfare of the society (since it as a whole has to carry the additional costs). A second effect arises if we consider the possibility that OTC trading is a substitute for exchange trading. Through vertical integration the cost of OTC trading could be raised, and, therefore, vertical integration can be a mechanism for a competitive advantage. Thus, for a given size of the OTC market, a higher degree of substitutability of the trading services between exchanges and OTC trading implies that vertical integration becomes more advantageous.

\section{Discussion}

\subsection{Multilateral Trading Facilities}

In recent years a large number of so called Multilateral Trading Facilities (MTFs) have emerged. These MTFs offer trading services in various ways. While some operate systems similar to traditional exchanges for special asset classes, others operate specialized systems as dark pools that do not quote realized prices. But all MTFs share one common characteristic: They do not offer listing services.

We interpret the emergence of MTFs in a similar way to OTC trading. MTFs are an additional alternative for trading that also needs a link to the CSDs, an inefficient one in the case of an integrated exchange. The introduction of MTFs has had three effects. First, it creates new trading activity, e.g., through faster systems. This activity lowers the attractiveness of vertical integration because the number of trades via the inefficient link increases. Second, it brings former bilateral OTC trading to more efficient centralized platforms and, third, substitutes away trading activity from traditional exchanges. In contrast to the first effect, these two latter effects may have increased the attractiveness of vertical integration. MTFs are still imperfect substitutes to exchanges but presumably closer to formal exchanges than simple OTC trading. The larger degree of substitutability with exchange services increases the relevance of costs. Therefore, increasing the costs of the rivals raises the possibility of deterring entry. Looking at the market shares in table 2 , this view seems to be supported by some initial empirical indications. Deutsche Börse, the more vertically integrated exchange, lost less market shares to new MTFs compared to the London Stock Exchange.

\begin{tabular}{lcc}
\hline & DAX 30 & FTSE 100 \\
\hline Market Share of MTFs & 23 percent & 32 percent \\
\hline \hline
\end{tabular}

Table 2: Market Share of $\mathrm{MTFs}^{6}$ in DAX 30 and FTSE 100 shares 2009. (Source: BATS Europe Website)

\footnotetext{
${ }^{6}$ BATS, Chi-X, Nasdaq OMX Europe MTF, and Turquoise.
} 
We also would like to stress another point that indicates that the underlying mechanisms in our model are in line with the stylized facts observed in this respect. Given the demand for liquidity and due to the fact that MTFs do not offer listing services, there is a priori no reason why the market should expect many people to trade any asset on their platforms; except one, lower prices. Indeed, we observe significantly lower trading prices with MTFs as compared to incumbent exchanges.

The emergence of MTFs raises a number of further issues. In order to be able to compete with the traditional exchanges MTFs have been very innovative in bypassing the expectation or liquidity advantage of the exchanges. They try to coordinate major players in the market on their platform, e.g. Turquoise, or introduce new pricing schemes like Maker-Taker pricing. Maker-Taker pricing schemes pay for every Limit-Order (e.g., an order that is contingent on a specific price, which therefore "makes" liquidity) and bill for every Market-Order (e.g., an order to buy/sell at the best available price, which therefore "takes" liquidity). In sum, the trading platforms earn a positive amount.

When they succeed in capturing the largest part of the liquidity, new questions about the industry structure arise. The listing entity will then be uncoupled with the trading platform. Traditional exchanges may then become a simple listing (or rating) agency and the prices for IPOs will potentially rise.

\subsection{Algo-Trading}

Algorithmic trading (AT) has increased greatly in the recent past. The typical definition for AT is the automatic trading of financial assets on the basis of computer algorithms. Behind this broad definition, a wide variety of different algorithmic patterns, such as statistical algorithms based on statistical arbitrage or splitting large orders into small ones, exist in the data (Hendershott, Jones, and Menkveld (2011)).

Since the 1990s it is possible to observe a correlation between this type of trading and increased liquidity. But since AT is a supplier of liquidity as well as a demander of liquidity, the net effect is not a priori clear. In a recent study, Hendershott, Jones, and Menkveld (2011), however, provide clear empirical evidence for a positive causal effect for AT on liquidity. They find that for large stocks in particular, AT reduces spreads and therefore benefits other non AT traders as well.

Because AT is present on a multiplicity of trading platforms, we interpret this as a reduction of the liquidity advantage of the home market (e.g., a reduction in $k$, i.e., less desire by traders for liquidity, harms primary markets, by the way, a fact which is correlated with the rise of AT) and, hence, makes vertical integration less appealing. With a lower $k$ more trades take place via the efficient links and more so via inefficient ones. This effect is especially pronounced where AT is most prevalent, namely in large stocks. That 
finding implies that due to the rise of AT exchanges that are in particular specialized in equity markets and even more so in large stocks have less incentives to vertically integrate.

\subsection{TARGET2-Securities}

TARGET2-Securities are an initiative by the Eurosystem with the objective of establishing an IT-platform that offers harmonized and central settlement services. This platform divides the settlement process from the other CSD services, e.g., safe-keeping. By connecting all involved CSDs, the main aim is to reduce the barriers and costs of cross-border trades.

In our model, TARGET2-Securities fit the horizontal integration case. All systems become compatible to each other and, hence, economies of scale and scope decrease the costs of settling trades. We interpret the fact that the Eurosystem, as a system of public entities, promotes such a system as a reaction on the perceived divergence of private and social incentives for vertical/horizontal integration. Given our results in Proposition 6 private actors opt for excessive vertical integration if the importance of liquidity is relatively weak. Thus, the move of the Eurosystem is justified against the background of our model, if the importance of liquidity over all asset classes is relatively weak and/or will decrease in the future. This seems to be the case as we have outlined in the former sections that some major industry trends, like the emergence of Algo-Trading and Multilateral Trading Facilities that include Maker-Taker Pricing, decrease the importance of liquidity. A presumably further declining $k$ makes horizontal integration therefore more desirable from a social point-of-view.

\section{Conclusion}

We consider the main contribution of this paper is to shed light on the inter-relation between the choice of organizational design and competition in the financial-security service industry. In order to do so we have developed a stylized model of the financial-security service industry. The key feature of the model is the competition among three differentiated exchanges (upstream producers) which each build on the services of the respective settlement providers (downstream producers). The latter act as monopolists since settlement is linked one-to-one to the platform where the listing of the financial security has taken place. A key advantage of the "home" exchange is delineated in the liquidity effect which

states traders' preferences for liquidity on a single platform. The liquidity effect as well as the degree of differentiation among exchanges together with the social net reservation price are the key drivers in our model. In this framework, vertical integration is considered as establishing a closed technological standard which allows for specific linkages between 
up- and downstream producer.

The main empirical predictions of our analysis are that we should expect to see less rather than more vertical integration if further real integration, e.g., in the European Union, prevails and cross-border trades become more attractive for investors. In addition, we should observe more vertical integration of exchanges which are relying on trading assets where the liquidity effect plays a crucial role (e.g. in stocks). Finally we stress the possibility of market failure and coordination problems among firms associated with the vertical integration decision process. We argue that this may lead to an equilibrium with excessive vertical integration from of social point of view but also from the firms' perspective.

Despite the fact that we have focused our analysis on financial-security service providers, we think a number of our insights can be applied to other network industries; such as the railway industry, the gas industry, etc. Adopting our framework to other industries should allow us to approach questions of organizational design such as the question of whether the network infrastructure should be closely aligned with one upstream firm or be operated independently.

\section{References}

Bulow, J., J. Geanakoplos, and P. Klemperer (1985): "Multimarket Oligopoly: Strategic Substitutes and Complements," The Journal of Political Economy, 93, 488511.

Di NoiA, C. (2002): "Competition and Integration among Stock Exchanges in Europe: Network Effects, Implicit Mergers and Remote Access," European Financial Management, 7, 39-72.

Economist (2006): "Battle of the bourses," The Economist.

FESE (2008): "European Exchange Report 2008," Federation of European Securities Exchanges.

Foucault, T., and C. Parlour (2004): "Competition for Listing," The RAND Journal of Economics, 35, 329-355.

Grossman, S., and O. Hart (1986): "The Costs and Benefits of Ownership: A Theory of Vertical and Lateral Integration," Journal of Political Economy, 94, 691-719.

Halling, M., M. Pagano, O. Randl, and J. Zechner (2008): "Where Is the Market? Evidence from Cross-Listings in the United States," The Review of Financial Studies, $21,725-761$. 
Hendershott, T., C. Jones, and A. Menkveld (2011): "Does Algorithmic Trading Improve Liquidity?," Journal of Finance.

Holthausen, C., and J. TAPking (2007): "Raising rivals costs in the securities settlement industry," Journal of Financial Intermediation, 16, 91-116.

Kaserer, C., And D. Schiereck (2008): "Primary Market Activity and the Cost of Going and Being Public," unpublished working paper.

Kauko, K. (2004): "The links between securities settlement systems: An olihopoly theoretic approach," International Review of Financial Analysis, 13, 585-600.

- (2007): "Interlinking securities settlement systems: A strategic commitment?," Journal of Banking and Finance, 31, 2962-2977.

Köppl, T., And C. Monnet (2007): "Guess what: Its the settlements! Vertical integration as a barrier to efficient exchange consolidation," Journal of Banking and Finance, $31,3013-3033$.

Rochet, J. (2005): "The Welfare Effects of Vertical Integration in the Securities Clearing and Settlement Industry," unpublished working paper.

Shy, O. (2001): The Economics of Networks. Cambridge University Press, Cambridge.

Shy, O., AND J. TARKKA (2001): "Stock exchange alliances, access fees and competition," Discussion paper, Finlands Bank, Bank of Finland Discussion Papers.

TAPKInG, J., AND J. YANG (2006): "Horizontal and Vertical Integration in Securities Trading and Settlement," Journal of Money, Credit, and Banking, 38, 1765-1795.

Tesar, L., and I. Werner (2008): "Home Bias and High Turnover," Journal of International Money and Finance, 14, 467-492.

Tirole, J. (1988): The Theory of Industrial Organization. The MIT Press, Cambridge. 


\section{Appendix}

\section{Derivation of price reaction functions and proof of Lemma 1}

In order to derive the profit-maximizing trading and settlement prices we plug in the demand functions in Eq. (8) as well as in Eq. (9) and take first-order derivatives with respect to prices. This procedure yields 12 reaction functions, for trading platform $i, j, l=$ $\{A, B, C\}$ we find:

$$
\begin{aligned}
p_{i}^{T}=\frac{1}{2 n_{i}+3 n_{j}+3 n_{l}} \quad & {\left[\frac{t}{6}\left(2 n_{i}+n_{j}+n_{l}\right)+\frac{k}{2}\left(2 n_{i}-n_{j}-n_{l}\right)+\right.} \\
& V\left(n_{j}+n_{l}\right)+\frac{c^{T}}{2}\left(2 n_{i}+3 n_{j}+3 n_{l}\right)+\frac{p_{j}^{T}}{2}\left(n_{i}+n_{j}\right)+ \\
& \frac{p_{l}^{T}}{2}\left(n_{i}+n_{l}\right)-n_{i} p_{i i}^{S}+\frac{1}{2}\left(n_{i} p_{i j}^{S}+n_{i} p_{i k}^{S}+n_{j} p_{j j}^{S}+n_{l} p_{l l}^{S}\right) \\
& \left.-\frac{3}{2}\left(n_{j} p_{j i}^{S}+n_{l} p_{l i}^{S}\right)\right]
\end{aligned}
$$

The corresponding settlement prices for $i \neq j \neq l$ are:

$$
\begin{aligned}
p_{i i}^{S} & =\frac{1}{2} c_{i i}^{S}+\frac{1}{2} k+\frac{1}{6} t-\frac{1}{2} p_{i}^{T}+\frac{1}{4}\left(p_{j}^{T}+p_{l}^{T}\right)+\frac{1}{2}\left(p_{i j}^{S}+p_{i l}^{S}\right)-\frac{1}{4}\left(c_{i j}^{S}+c_{i l}^{S}\right) \\
p_{i j}^{S} & =\frac{1}{2} c_{i j}^{S}-\frac{1}{6} k+\frac{1}{18} t+\frac{1}{6} p_{i}^{T}-\frac{1}{2} p_{j}^{T}+\frac{1}{3} p_{i i}^{S}-\frac{1}{6} c_{i i}^{S}+\frac{1}{3} V
\end{aligned}
$$


Combining these prices yields for $n_{B}=n_{C}=\frac{1-n_{A}}{2}$ (when we are analyzing asymmetries, we analyze them in one dimension keeping the others symmetric):

$p_{A}^{T}=\frac{1}{12\left(29+n_{A}-4 n_{A}^{2}\right)}\left[24 c^{T}\left(11+2 n_{A}-n_{A}^{2}\right)+12 k\left(3 n_{A}^{2}+8 n_{A}-3\right)+4 t\left(n_{A}^{2}+5 n_{A}+4\right)+12 V\left(7-3 n_{A}-2 n_{A}^{2}\right)-24 n_{A} c_{A A}^{S}\left(n_{A}-3\right)+6 n_{A}\left(c_{A B}^{S}+c_{A C}^{S}\right)\left(n_{A}+5\right)+\right.$ $\left.6\left(c_{B B}^{S}+c_{C C}^{S}\right)\left(3-2 n_{A}-n_{A}^{2}\right)+3\left(c_{B C}^{S}+c_{C B}^{S}\right)\left(n_{A}^{2}-1\right)+3\left(c_{B A}^{S}+c_{C A}^{S}\right)\left(7 n_{A}^{2}+12 n_{A}-19\right)\right]$

$p_{B}^{T}=\frac{1}{12\left(493+46 n_{A}-67 n_{A}^{2}-4 n_{A}^{3}\right)}\left[24 c^{T}\left(204-5 n_{A}-18 n_{A}^{2}-n_{A}^{3}\right)+12 k\left(34-117 n_{A}+44 n_{A}^{2}+3 n_{A}^{3}\right)+4 t\left(119-61 n_{A}+13 n_{A}^{2}+n_{A}^{3}\right)+12 V\left(85+56 n_{A}-31 n_{A}^{2}-2 n_{A}^{3}\right)+\right.$ $24 n_{A} c_{A A}^{S}\left(34-15 n_{A}-n_{A}^{2}\right)-6 n_{A} c_{A B}^{S}\left(395-66 n_{A}+29 n_{A}^{2}\right)-6 n_{A} c_{A C}^{S}\left(47-78 n_{A}+19 n_{A}^{2}\right)-6 c_{B B}^{S}\left(121-133 n_{A}-n_{A}^{2}+13 n_{A}^{3}\right)+6 c_{C C}^{S}\left(53-35 n_{A}-29 n_{A}^{2}+11 n_{A}^{3}\right)+$ $\left.3 c_{B C}^{S}\left(79-29 n_{A}-79 n_{A}^{2}+29 n_{A}^{3}\right)-3 c_{C B}^{S}\left(385-419 n_{A}-n_{A}^{2}+35 n_{A}^{3}\right)+3 c_{B A}^{S}\left(109-155 n_{A}+35 n_{A}^{2}+11 n_{A}^{3}\right)-c_{C A}^{S}\left(211+129 n_{A}-165 n_{A}^{2}+15 n_{A}^{3}\right)\right]$

$p_{C}^{T}=\frac{1}{12\left(493+46 n_{A}-67 n_{A}^{2}-4 n_{A}^{3}\right)}\left[24 c^{T}\left(204-5 n_{A}-18 n_{A}^{2}-n_{A}^{3}\right)+12 k\left(34-117 n_{A}+44 n_{A}^{2}+3 n_{A}^{3}\right)+4 t\left(119-61 n_{A}+13 n_{A}^{2}+n_{A}^{3}\right)+12 V\left(85+56 n_{A}-31 n_{A}^{2}-2 n_{A}^{3}\right)+\right.$ $24 n_{A} c_{A A}^{S}\left(34-15 n_{A}-n_{A}^{2}\right)-6 n_{A} c_{A C}^{S}\left(395-66 n_{A}+29 n_{A}^{2}\right)-6 n_{A} c_{A B}^{S}\left(47-78 n_{A}+19 n_{A}^{2}\right)-6 c_{C C}^{S}\left(121-133 n_{A}-n_{A}^{2}+13 n_{A}^{3}\right)+6 c_{B B}^{S}\left(53-35 n_{A}-29 n_{A}^{2}+11 n_{A}^{3}\right)+$ $\left.3 c_{C B}^{S}\left(79-29 n_{A}-79 n_{A}^{2}+29 n_{A}^{3}\right)-3 c_{B C}^{S}\left(385-419 n_{A}-n_{A}^{2}+35 n_{A}^{3}\right)+3 c_{C A}^{S}\left(109-155 n_{A}+35 n_{A}^{2}+11 n_{A}^{3}\right)-c_{B A}^{S}\left(211+129 n_{A}-165 n_{A}^{2}+15 n_{A}^{3}\right)\right]$

$p_{A A}^{S}=\frac{1}{8\left(29+n_{A}-4 n_{A}^{2}\right)}\left[\left(V-c^{T}\right)\left(88+16 n_{A}-8 n_{A}^{2}\right)+k\left(128-28 n_{A}-28 n_{A}^{2}\right)+t\left(72-4 n_{A}-12 n_{A}^{2}\right)+4 c_{A A}^{S}\left(29+7 n_{A}-2 n_{A}^{2}\right)-2 n_{A}\left(c_{A B}^{S}+c_{A C}^{S}\right)\left(5+n_{A}\right)-\right.$ $\left.2\left(c_{B B}^{S}+c_{C C}^{S}\right)\left(3-2 n_{A}-1 n_{A}^{2}\right)+\left(c_{B C}^{S}+c_{C B}^{S}\right)\left(1-n_{A}^{2}\right)+\left(c_{B A}^{S}+c_{C A}^{S}\right)\left(19-12 n_{A}-7 n_{A}^{2}\right)\right]$

$p_{A q}^{S}=\frac{1}{24\left(493+46 n_{A}-67 n_{A}^{2}-4 n_{A}^{3}\right)}\left[24\left(V-c^{T}\right)\left(204-5 n_{A}-18 n_{A}^{2}-n_{A}^{3}\right)-6 k\left(68-234 n_{A}+88 n_{A}^{2}+6 n_{A}^{3}\right)-4 t\left(374-107 n_{A}+80 n_{A}^{2}+5 n_{A}^{3}\right)-24 n_{A} c_{A A}^{S}\left(34-15 n_{A}-n_{A}^{2}\right)+\right.$ $6 c_{A q}^{S}\left(986+487 n_{A}-200 n_{A}^{2}-37 n_{A}^{3}\right)+6 n_{A} c_{A p}^{S}\left(47-78 n_{A}+19 n_{A}^{2}\right)+6 c_{q q}^{S}\left(121-133 n_{A}-n_{A}^{2}+13 n_{a}^{3}\right)-6 c_{p p}^{S}\left(53-35 n_{A}-29 n_{A}^{2}+11 n_{A}^{3}\right)-3 c_{q p}^{S}\left(79-29 n_{A}-79 n_{A}^{2}+29 n_{A}^{3}\right)+$ $\left.3 c_{p q}^{S}\left(385-419 n_{A}-n_{A}^{2}+35 n_{A}^{3}\right)-3 c_{q A}^{S}\left(109-155 n_{A}+35 n_{A}^{2}+11 n_{A}^{3}\right)+3 c_{p A}^{S}\left(7+43 n_{A}-55 n_{A}^{2}+5 n_{A}^{3}\right)\right]$

$p_{q q}^{S}=\frac{1}{8\left(493+46 n_{A}-67 n_{A}^{2}-4 n_{A}^{3}\right)}\left[8\left(V-c^{T}\right)\left(204-5 n_{A}-18 n_{A}^{2}-n_{A}^{3}\right)+4 k\left(459+163 n_{A}-111 n_{A}^{2}-7 n_{A}^{2}\right)-4 t\left(289-51 n_{A}+49 n_{A}^{2}+3 n_{A}^{3}\right)-8 n_{A} c_{A A}^{S}\left(34+15 n_{A}-n_{A}^{2}\right)+\right.$ $2 n_{A} c_{A q}^{S}\left(395-66 n_{A}-29 n_{A}^{2}\right)+2 n_{A} c_{A p}^{S}\left(47-78 n_{A}+19 n_{A}^{2}\right)+2 c_{q q}^{S}\left(1107-41 n_{A}-135 n_{A}^{2}+5 n_{A}^{3}\right)-2 c_{p p}^{S}\left(53-35 n_{A}-29 n_{A}^{2}+11 n_{A}^{3}\right)-c_{q p}^{S}\left(79-29 n_{A}-79 n_{A}^{2}+29 n_{A}^{3}\right)+$ $\left.c_{p q}^{S}\left(385-419 n_{A}-n_{A}^{2}+35 n_{A}^{3}\right)-c_{q A}^{S}\left(109-155 n_{A}+35 n_{A}^{2}+11 n_{A}^{3}\right)+c_{p A}^{S}\left(7+43 n_{A}-55 n_{A}^{2}+5 n_{A}^{3}\right)\right]$

$p_{q A}^{S}=\frac{1}{24\left(29+n_{A}-4 n_{A}^{2}\right)}\left[24\left(V-c^{T}\right)\left(11+2 n_{A}+n_{A}^{2}\right)+6 k\left(6-16 n_{A}+6 n_{A}^{2}\right)+4 t\left(25-4 n_{A}-5 n_{A}^{2}\right)+24 n_{A} c_{A A}^{S}\left(3+n_{A}\right)-6 n_{A}\left(c_{A q}^{S}+c_{A p}^{S}\right)\left(5+n_{A}\right)-6\left(c_{q q}^{S}+c_{p p}^{S}\right)\left(3-2 n_{A}-n_{A}^{2}\right)+\right.$ $\left.3\left(c_{q p}^{S}+c_{p q}^{S}\right)\left(1-n_{A}^{2}\right)+c_{q A}^{S}\left(135-8 n_{A}-23 n_{A}^{2}\right)+3 c_{p A}^{S}\left(19-12 n_{A}-7 n_{A}^{2}\right)\right]$

$p_{q p}^{S}=\frac{1}{24\left(493+46 n_{A}-67 n_{A}^{2}-4 n_{A}^{3}\right)}\left[-24 c^{T}\left(204-5 n_{A}-18 n_{A}^{2}-n_{A}^{3}\right)-12 k\left(34-117 n_{A}+444 n_{A}^{2}+3 n_{A}^{3}\right)+4 t\left(374-77 n_{A}+80 n_{A}^{2}+5 n_{A}^{3}\right)+24 V\left(204-5 n_{A}-18 n_{A}^{2}-n_{A}^{3}\right)-\right.$ $24 n_{A} c_{A A}^{S}\left(34-15 n_{A}-n_{A}\right)+6 n_{A} c_{A q}^{S}\left(47-78 n_{A}+19 n_{A}^{2}\right)+6 n_{A} c_{A p}^{S}\left(395-66 n_{A}-29 n_{A}^{2}\right)-6 c_{q q}^{S}\left(53-35 n_{A}-29 n_{A}^{2}+11 n_{A}^{3}\right)+6 c_{p p}^{S}\left(121-133 n_{A}-n_{A}^{2}+13 n_{A}^{3}\right)+$ $\left.3 c_{q p}^{S}\left(2357-235 n_{A}-269 n_{A}^{2}+19 n_{A}^{3}\right)-3 c_{p q}^{S}\left(79-29 n_{A}-79 n_{A}^{2}+29 n_{A}^{3}\right)+3 c_{q A}^{S}\left(7+43 n_{A}-55 n_{A}^{2}+5 n_{A}^{3}\right)-3 c_{p A}^{S}\left(109-155 n_{A}+35 n_{A}^{2}+11 n_{A}^{3}\right)\right]$ 
Plugging in the respective costs and $n_{i}=\frac{1}{3}$ yields

$$
\begin{aligned}
p_{A}^{T} & =\frac{1}{5} V-\frac{1}{5} c^{S}+\frac{4}{5} c^{T}+\frac{1}{15} t-\frac{7}{65} y \\
p_{B}^{T}=p_{C}^{T} & =\frac{1}{5} V-\frac{1}{5} c^{S}+\frac{4}{5} c^{T}+\frac{1}{15} t-\frac{19}{130} y \\
p_{A A}^{S} & =\frac{2}{5} V+\frac{3}{5} c^{S}-\frac{2}{5} c^{T}+\frac{3}{10} t+\frac{1}{2} k-\frac{29}{65} y \\
p_{B B}^{S}=p_{C C}^{S} & =\frac{2}{5} V+\frac{3}{5} c^{S}-\frac{2}{5} c^{T}+\frac{3}{10} t+\frac{1}{2} k+\frac{19}{260} y \\
p_{A B}^{S}=p_{A C}^{S} & =\frac{2}{5} V+\frac{3}{5} c^{S}-\frac{2}{5} c^{T}+\frac{2}{15} t+\frac{149}{260} y \\
p_{B A}^{S}=p_{C A}^{S} & =\frac{2}{5} V+\frac{3}{5} c^{S}-\frac{2}{5} c^{T}+\frac{2}{15} t+\frac{36}{65} y \\
p_{B C}^{S}=p_{C B}^{S} & =\frac{2}{5} V+\frac{3}{5} c^{S}-\frac{2}{5} c^{T}+\frac{2}{15} t+\frac{19}{260} y
\end{aligned}
$$

These prices allow us to state Lemma 1 


\section{Proof of Lemma 2}

By inserting the prices into the demand functions we get

$d_{A}^{A}=\frac{1}{12\left(29+n_{A}-4 n_{A}^{2}\right)}\left[\left(V-c^{T}\right)\left(36 n_{A}-12\right)+k\left(204-84 n_{A}-24 n_{A}^{2}\right)+t\left(64-16 n_{A}-8 n_{A}^{2}\right)-6 c_{A A}^{S}\left(29-9 n_{A}-4 n_{A}^{2}\right)+3\left(c_{A B}^{S}+c_{A C}^{S}\right)\left(29-17 n_{A}\right)-15\left(c_{B B}^{S}+c_{C C}^{S}\right)\left(1-n_{A}\right)+\right.$ $\left.\left.3\left(c_{B A}^{S}+c_{C A}^{S}\right)\left(11-9 n_{A}-2 n_{A}^{2}\right)-6\left(c_{B C}^{S}+c_{C B}^{S}\right)\left(2-3 n_{A}+n_{A}^{2}\right)\right]\right]$

$d_{A}^{q}=\frac{1}{8\left(493+46 n_{A}-67 n_{A}^{2}-4 n_{A}^{3}\right)}\left[4\left(V-c^{T}\right)\left(357+140 n_{A}-27 n_{A}^{2}-2 n_{A}^{3}\right)-4 k\left(153+281 n_{A}+33 n_{A}^{2}+n_{A}^{3}\right)-4 t\left(68+47 n_{A}+208 n_{A}^{2}+n_{A}^{3}\right)+4 n_{A} c_{A A}^{S}\left(187+90 n_{A}+n_{A}^{2}\right)-\right.$ $2 n_{A} c_{A q}^{S}\left(325-13 n_{A}^{2}\right)-2 c_{A p}^{S}\left(151-6 n_{A}+11 n_{A}^{2}\right)+2 c_{q q}^{S}\left(356+159 n_{A}-38 n_{A}^{2}-9 n_{A}^{3}\right)-2 c_{p p}^{S}\left(50-29 n_{A}-14 n_{A}^{2}-7 n_{A}^{3}\right)+13 c_{q p}^{S}\left(5-n_{A}-5 n_{A}^{2}+n_{A}^{3}\right)-c_{q A}^{S}\left(2419+631 n_{A}-223 n_{A}^{2}-19 n_{A}^{3}\right)+$ $\left.\left.13 c_{p A}^{S}\left(37-23 n_{A}-13 n_{A}^{2}+n_{A}^{3}\right)-c_{p q}^{S}\left(167-211 n_{A}+25 n_{A}^{2}+19 n_{A}^{3}\right)\right]\right]$

$d_{q}^{A}=\frac{1}{8\left(493+46 n_{A}-67 n_{A}^{2}-4 n_{A}^{3}\right)}\left[4\left(V-c^{T}\right)\left(425-60 n_{A}-39 n_{A}^{2}-2 n_{A}^{3}\right)-4 k\left(323-219 n_{A}+3 n_{A}^{2}+n_{A}^{3}\right)+4 t\left(34+53 n_{A}-14 n_{A}^{2}+n_{A}^{3}\right)+2 c_{A A}^{S}\left(448-260 n_{A}-17 n_{A}^{2}\right)-\right.$

$2 c_{A q}^{S}\left(1479-497 n_{A}-113 n_{A}^{2}+31 n_{A}^{3}\right)+2 c_{A_{p}}^{S}\left(113-106 n_{A}+291 n_{A}^{2}\right)+2 c_{q q}^{S}\left(207-215 n_{A}+11 n_{A}^{2}+19 n_{A}^{3}\right)-2 c_{p p}^{S}\left(54-37 n_{A}-34 n_{A}^{2}+17 n_{A}^{3}\right)-c_{q p}^{S}\left(127-43 n_{A}-127 n_{A}^{2}+43 n_{A}^{3}\right)-$

$\left.\left.c_{p A}^{S}\left(151-157 n_{A}+17 n_{A}^{2}-11 n_{A}^{3}\right)-13 c_{q A}^{S}\left(25-25 n_{A}-n_{A}^{2}+n_{A}^{3}\right)+c_{p q}^{S}\left(569-629 n_{A}+7 n_{A}^{2}+53 n_{A}^{3}\right)\right]\right]$

$d_{q}^{q}=\frac{1}{12\left(29+n_{A}-4 n_{A}^{2}\right)\left(17+n_{A}\right)}\left[2\left(V-c^{T}\right)\left(51-150 n_{A}-9 n_{A}^{2}\right)+3 k\left(901+342 n_{A}-119 n_{A}^{2}+6 n_{A}^{3}\right)-t\left(935-242 n_{A}+125 n_{A}^{2}+8 n_{A}^{3}\right)+30 n_{A} c_{A A}^{S}\left(17+10 n_{A}\right)+2 n_{A} c_{A q}^{S}\left(621-24 n_{A}-67 n_{A}^{2}\right)-(45)\right.$ $6 n_{A} c_{A p}^{S}\left(54+17 n_{A}-17 n_{A}^{2}\right)-c_{q q}^{S}\left(2439+774 n_{A}-327 n_{A}^{2}-78 n_{A}^{3}\right)-6 c_{p p}^{S}\left(44-43 n_{A}-10 n_{A}^{2}+9 n_{A}^{3}\right)+3 c_{q p}^{S}\left(353+165 n_{A}-23 n_{A}^{2}-27 n_{A}^{3}\right)-3 c_{p A}^{S}\left(50-29 n_{A}-14 n_{A}^{2}-7 n_{A}^{3}\right)+$ $\left.\left.c_{q A}^{S}\left(356+159 n_{A}-38 n_{A}^{2}-9 n_{A}^{3}\right)+c_{p q}^{S}\left(624-651 n_{A}-48 n_{A}^{2}+75 n_{A}^{3}\right)\right]\right]$

$d_{q}^{p}=\frac{1}{8\left(493+46 n_{A}-67 n_{A}^{2}-4 n_{A}^{3}\right)}\left[8\left(V-c^{T}\right)\left(204-5 n_{A}-18 n_{A}^{2}-n_{A}^{3}\right)-2 k\left(561+188 n_{A}-21 n_{A}^{2}-2 n_{A}^{3}\right)+2 t\left(85+66 n_{A}-31 n_{A}^{2}-2 n_{A}^{3}\right)+8 n_{A} c_{A A}^{S}\left(34-15 n_{A}-n_{A}^{2}\right)+\right.$ $2 n_{A} c_{A q}^{S}\left(569-60 n_{A}-53 n_{A}^{2}\right)-2 n_{A} c_{A p}^{S}\left(127+84 n_{A}-43 n_{A}^{2}\right)+2 c_{q q}^{S}\left(208-217 n_{A}-16 n_{A}^{2}+25 n_{A}^{3}\right)+2 c_{p p}^{S}\left(353+165 n_{A}-23 n_{A}^{2}-27 n_{A}^{3}\right)-c_{q p}^{S}\left(311-253 n_{A}-119 n_{A}^{2}+61 n_{A}^{3}\right)-$ $\left.\left.13 c_{p A}^{S}\left(5-n_{A}-5 n_{A}^{2}-n_{A}^{3}\right)+c_{q A}^{S}\left(167+211 n_{A}+25 n_{A}^{2}+19 n_{A}^{3}\right)+c_{p q}^{S}\left(2341+919 n_{A}-361 n_{A}^{2}-91 n_{A}^{3}\right)\right]\right]$ 
Substituting these expressions into the respective expressions yields for market coverage and number of traders on the respective platforms the following expressions. For

securities listed on trading platform A, traders which remain inactive for those securities are:

$$
\frac{1}{3}-d_{B B}^{A}-d_{C C}^{A}=\frac{286 t-312 v+333 y}{390 t}
$$

Number of traders trading platform A for securities listed on A can be expressed as

$$
d_{A B}^{A}+d_{A C}^{A}=\frac{78 k+26 t+153 y}{156 t} .
$$

The corresponding effects for securities listed on $\mathrm{B}$ and $\mathrm{C}$ with $p, q=\{B, C\}$ and $p \neq q$ are:

$$
1-d_{A A}^{q}+d_{p p}^{q}=\frac{572 t-624 v+291 y}{780 t}
$$

for the size of the inactive traders and

$$
d_{q A}^{q}+d_{q p}^{q}=\frac{156 k+52 t+81 y}{312 t}
$$

for trades taking place on the platforms on which the securities are actually listed.

\section{Derivation of profit functions}

Substituting prices and quantities into Eqs.(8) and (9) gives the relevant profits and the relevant differences follow. 


\section{Derivation of trader surplus for the different settings}

We can express trader surplus as the sum of consumer surplus of all the different segments:

$$
\begin{aligned}
T S= & n_{1}\left[\int_{0}^{x_{1}^{A}}\left(V-p_{A}^{T}-p_{A A}^{S}+k-t x\right) d x+\int_{x_{1}^{A}}^{\frac{1}{3}}\left(V-p_{B}^{T}-p_{A B}^{S}-t *\left(\frac{1}{3}-x\right)\right) d x+\right. \\
& \int_{\frac{1}{3}}^{x_{3}^{A}}\left(V-p_{B}^{T}-p_{A B}^{S}-t\left(x-\frac{1}{3}\right) d x+\int_{x_{4}^{A}}^{\frac{2}{3}}\left(V-p_{C}^{T}-p_{A C}^{S}-t\left(\frac{2}{3}-x\right) d x+\right.\right. \\
& \int_{\frac{2}{3}}^{x_{2}^{A}}\left(V-p_{C}^{T}-p_{A C}^{S}-t\left(x-\frac{2}{3}\right) d x+\int_{x_{2}^{A}} 1\left(V-p_{A}^{T}-p_{A A}^{S}+k-t(1-x)\right) d x\right]+ \\
& n_{2}\left[\int_{0}^{x_{1}^{B}}\left(V-p_{A}^{T}-p_{B A}^{S}-t x\right) d x+\int_{x_{1}^{B}}^{1 / 3}\left(V-p_{B}^{T}-p_{B B}^{S}+k-t((1 / 3)-x)\right) d x+\right. \\
& \int_{1 / 3}^{x_{3}^{B}}\left(V-p_{B}^{T}-p_{B B}^{S}+k-t(x-(1 / 3)) d x+\int_{x_{3}^{B}}^{2 / 3}\left(V-p_{C}^{T}-p_{B C}^{S}-t((2 / 3)-x)\right) d x+\right. \\
& \int_{2 / 3}^{x_{4}^{B}}\left(V-p_{C}^{T}-p_{B C}^{S}-t(x-(2 / 3)) d x+\int_{x_{2}^{B}}^{1}\left(V-p_{A} T-p_{B A}^{S}-t(1-x)\right) d x\right]+ \\
& n_{3}\left[\int_{0}^{x_{1}^{C}}\left(V-p_{A}^{T}-p_{C A}^{S}-t x\right) d x+\int_{x_{4}^{C}}^{1 / 3}\left(V-p_{B}^{T}-p_{C B}^{S}-t((1 / 3)-x) d x+\right.\right. \\
& \int_{1 / 3}^{x_{3}^{C}}\left(V-p_{B}^{T}-p_{C B}^{S}-t(x-(1 / 3)) d x+\int_{x_{3}^{C}}^{2 / 3}\left(V-p_{C}^{T}-p_{C C}^{S}+k-t((2 / 3)-x) d x+\right.\right. \\
& \int_{2 / 3}^{x_{2}^{C}}\left(V-p_{C}^{T}-p_{C C}^{S}+k-t(x-(2 / 3)) d x+\int_{x_{2}^{C}}^{1}\left(V-p_{A}^{T}-p_{C A}^{S}-t(1-x)\right) d x\right. \\
& \\
& \\
&
\end{aligned}
$$

Plugging in the respective equilibrium prices for the symmetric case with vertical integration of only A yields after some tedious calculations:

$$
T S=\frac{\left(64896 v\left(\frac{3}{2} v+t-2 y\right)+50700 k\left(\frac{3}{2} k+t+3 y\right)-115934 t^{2}+7436 t y+203289 y^{2}\right.}{608400 t}
$$

For the symmetric case with vertical integration of all financial-security service provider we get

$$
T S=\frac{\left(192 v\left(\frac{3}{2} v+t-2 y\right)+150 k\left(\frac{3}{2} k+t+6 y\right)-343 t^{2}+108 t y+1188 y^{2}\right.}{1800 t}
$$

and for horizontal integration

$$
T S=\frac{\left(192\left(\frac{3}{2} v+t+3 b y\right)+150 k\left(\frac{3}{2} k+t\right)-343 t^{2}+192 t b y+288 b^{2} y^{2}\right.}{1800 t}
$$

Welfare is then calculated as the sum of consumer surplus and the sum of profits. 


\section{Proof of Proposition 2}

\section{Part i)}

The fact that vertical integration is privately more attractive if all other platforms are already vertically integrated as compared to a situation in which the other platforms are not yet vertically can be seen as follows. When computing our profit difference for A we get:

$$
\Delta\left(\pi_{A}^{S}+\pi_{A}^{T}\right)_{A+B}=y \frac{36075 k+6097 t-17784 v+47160 y}{152100 t}
$$

The denominator of this expression is lowest, if we, against the background of our assumptions allow for the lowest $k\left(k=\frac{1}{3} t\right)$ and $y(y=0)$ as well as for the highest feasible $v\left(v=\frac{11}{12} t\right)$. With these parameter combinations we get for the term in brackets in the denominator of Eq. (55)

$$
(12025 t+6097 t-16302 t)=1820 t>0
$$

\section{Part ii)}

More interesting is now the comparison of private profits of the financial-security service providers. The difference of A's profit amounts to

$$
\Delta\left(\pi_{A}^{S}+\pi_{A}^{T}\right)=y \frac{75 k+t-72 V+111 y}{225 t}
$$

Comparing this with Eq. (13) shows that now the Delta is positive for a smaller set of parameters.

\section{Proof of Proposition 3}

We compare Eqs. (13) and (16). We set Eq. (13) equal to zero and solve for $k$. Inserting this $\mathrm{k}$ into Eq. (16) gives us, after evaluating at $y=0$ the following expression for the numerator of Eq. (16):

$$
-\frac{24107241610 v+8158948200 t}{189900}<0
$$

Hence, if private incentives leave platform A just indifferent, stand-alone integration leads to lower welfare, thereby proving our claim.

\section{Proof of Proposition 4}

We compare Eqs. (13) and (17). We set Eq. (13) equal to zero and solve for $k$. Inserting this $\mathrm{k}$ into Eq. (17) gives us, after evaluating at $y=0$ the following expression for the numerator of Eq. (17):

$$
\frac{842400 v+220050 t}{198900}>0
$$

Hence, if private incentives leave platform A just indifferent, full-integration leads, compared to no integration to a higher social welfare level, thereby proving our claim. 


\section{Derivation of Eq. (18)}

With horizontal integration we derive from Eqs. (10)-(12) the following prices in equilibrium:

$$
\begin{aligned}
p_{i}^{T} & =\frac{1}{5} V-\frac{1}{5} c^{S}+\frac{12}{15} c^{T}+\frac{1}{15} t+\frac{1}{5} b y \\
p_{i i}^{S} & =\frac{2}{5} V+\frac{3}{5} c^{S}-\frac{2}{5} c^{T}+\frac{1}{2} k+\frac{3}{10} t-\frac{3}{5} b y \\
p_{i j}^{S} & =\frac{2}{5} V+\frac{3}{5} c^{S}-\frac{2}{5} c^{T}+\frac{2}{15} t-\frac{3}{5} b y
\end{aligned}
$$

Plugging these prices into the demand functions of the trading platforms allows us to derive the following differential profit expression for all settlement provider (i.e. the sum of settlement providers' profits after horizontal integration minus the one before integration):

$$
\Delta\left(\pi_{A}^{s}+\pi_{B}^{s}+\pi_{C}^{s}\right)=8 b y \frac{2 t+6 v+3 b y}{75 t} .
$$

